Document downloaded from:

http://hdl.handle.net/10251/66294

This paper must be cited as:

Galindo, J.; Luján, JM.; Climent, H.; Guardiola, C.; Varnier, O. (2014). A New Model for Matching Advanced Boosting Systems to Automotive Diesel Engines. SAE International Journal of Engines. 7(1):1-14. https://doi.org/10.4271/2014-01-1078

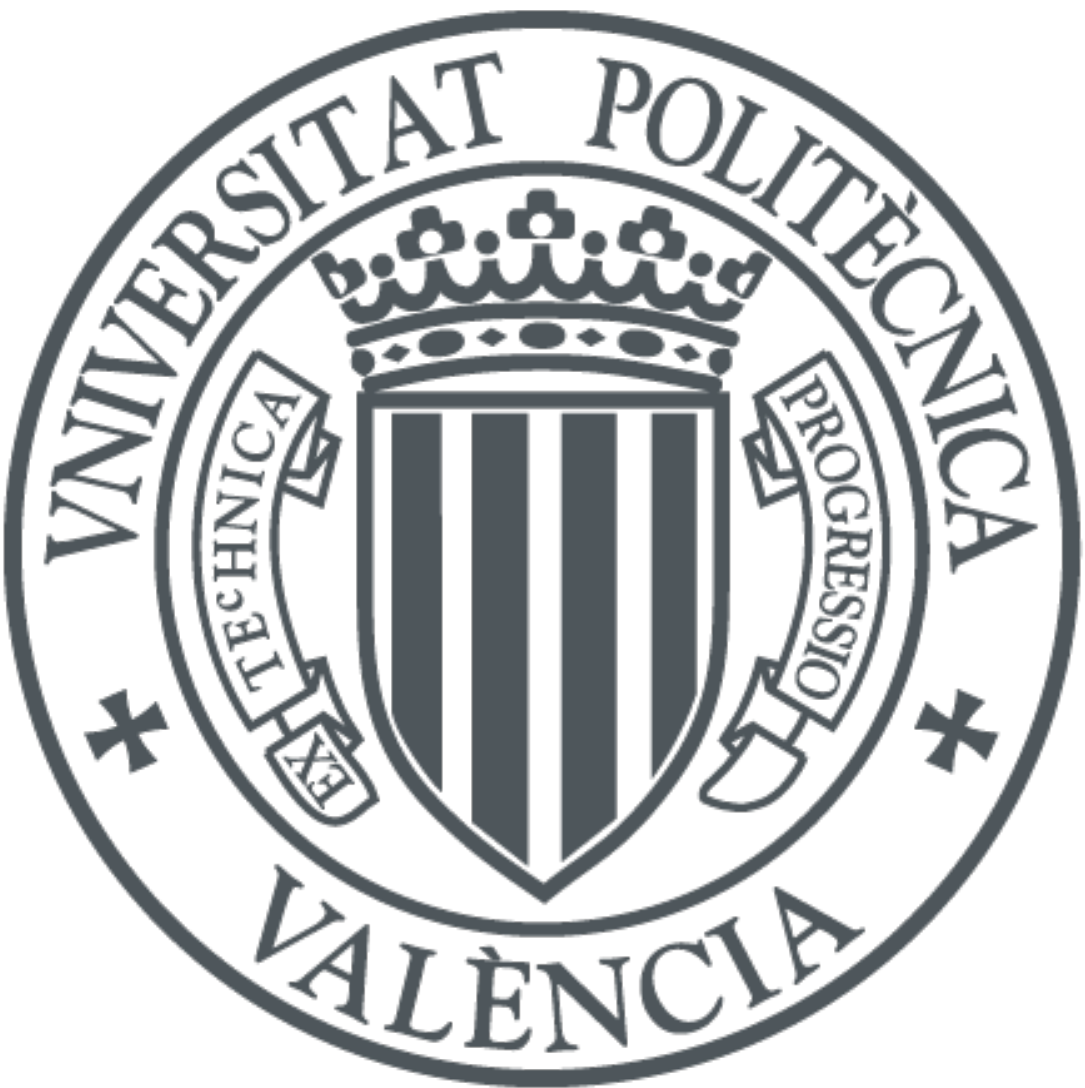

The final publication is available at

http://dx.doi.org/10.4271/2014-01-1078

Copyright SAE International

Additional Information 


\section{A new model for matching advanced boosting systems to automotive diesel engines}

José Galindo, José M. Lujan, Hector Climent, Carlos Guardiola. CMT-Motores Térmicos. Universidad Politècnica de València. Spain.

Olivier Varnier. Jaguar Land Rover Ltd. United Kingdom.

\section{Abstract}

Boosting technologies have been key enablers for automotive engines development through downsizing and downspeeding. In this situation, numerous multistage boosting systems have appeared in the last decade. The complexity arising from multistage architectures requires an efficient matching methodology to obtain the best overall powertrain performance.

The paper presents a model aimed to choose the best 2-stage boosting system architecture able to meet required criteria on boosting pressure, EGR ratios for both short and long route loops while respecting the engine thermo-mechanical limits such as in-cylinder pressure, compressor outlet temperature and exhaust manifold temperature. The model includes filling-and-emptying OD elements together with mean value. The engine model is set in a way that, for given requirements and boosting system layout, calculates in seconds if the requirements will be achieved and the position of variable geometry, waste-gate, EGR and by-pass valves. The model is thus inversed thanks to a new representation of turbine maps that converts the classical iterative matching procedure in straight forward. The model can be also used in a predictive manner to calculate the engine transient response.

The model has been calibrated to 3 different turbocharged diesel engines. The model gives good results provided that wave effects are not important. This is the case of compact exhaust manifolds, typically used in turbocharged diesel engines, below $3500 \mathrm{rpm}$. Tuned intake air lines can be taken into account through a tuning parameter affecting boosting pressure.

An example is given in the paper for the matching procedure in a 2-stage, double route EGR, including steady and transient results.

\section{Introduction}

The complexity arising from multistage architectures requires an efficient matching methodology to obtain the best overall powertrain performance. With a large number of components interacting between each other's, optimization processes are more and more exigent and only a correct combination of experimental techniques and simulation tools can lead to good results under suitable development time. To complete these tools, the second part of the methodology is based on a whole engine model able to correctly match the boosting system in steady-state conditions and to reproduce its performance under transient operations.

Different types of models are present in engine development and can be classified according to their complexity and computational cost. Each type has its pros and cons and their selection must be adapted to the specific application with a right balance between physical description, predictive capabilities, computational speed and accuracy [1][2]. There is lot of information in the literature about these different modeling approaches. So only a brief description of their main characteristics will be provided here and interesting reviews of thermodynamics models applied to the Diesel engine can be found in [3][4][5]. 
2D/3D Computational Fluid Dynamics (CFD), are the most predictive simulations because they solve the full unsteady Navier-Stokes equations set. They provide very detailed information of internal processes but require important computational resources. That is why they are generally restricted to local studies or in-cylinder simulations where fuel spray, turbulent combustion and chemical kinetics need a very small characteristic time scale to be predicted [6].

1D approach is a reduction of CFD models assuming only one dimension in the Navier-Stokes equations. Well established 1D codes such as GT-Power, WAVE, AVL Boost or the open source available OpenWAM [7] solve the mass, momentum and energy conservation equations in piping systems with finite differential or finite volume schemes [8][9], and employ particular boundary conditions in the different connections. They give an accurate description of complex gas dynamic phenomena in the intake and exhaust lines [10] but their computational time is relatively slow, in the order of 100-1000 times greater than real time. Their highly resolved gas exchange and cycle simulation are normally employed in engine development processes where inertia or wave effects could be important such as air delivery ratio optimization, variable valve timing calibration, manifold design, etc.

OD Filling \& Emptying Models (FEM) represent the engine components as a series of interconnected control volumes (cylinder, manifold, intercooler, etc.) and connecting elements (valve, restrictions, etc.). They solve the mass and energy conservation equations with time steps in the order of one crank angle to obtain instantaneous state of the gas within the different volumes. They exhibit for a moderate computational cost a relatively good prediction of the engine performance in both steady and transient conditions. Nevertheless, by ignoring the momentum conservation equation and without spatial resolution, they bring a further reduction to the Navier-Stokes equations which, even if engine aspiration is physically captured, make them unable to predict inertia and wave effects in the manifolds. Depending of the operating conditions and engine geometry, errors can be significant. Winterbone et al. [11] and Watson et al. [12][13] were the first in the late 1970's to introduce FEM in engine development to simulate turbocharger response. Since that, these models have also been largely used in control design and fault diagnosis [14][15].

Mean Value Engine Models (MVEM) have the same origin than FEM. They integrate transfer components and different volumes where the mass and energy conservation equations are resolved. But their resolutions are time-based and predict only mean values variations [16][17][18]. With time step in the order of one revolution, sub-cycle processes such as combustion or flow through valves are simplified by empirical correlations or map based models. MVEM are therefore not predictive and rely mainly on data obtained from measurements or high fidelity models. Their calibrations employ identification techniques and require a large amount of comprehensive engine data over a wide operating range, especially when nonlinearity and interaction between engine variables are significant. The main advantage of MVEM reside in their real time capabilities which make them particularly favorable for control and observer design. Hendricks et al. [19][20][21] were the first to develop MVEM for control supervision. Then numerous authors have integrated other empirical or semi-empirical methods (analytical derivations, radial basis functions [22][23], neural networks [24][25], etc.) to improve simulation accuracy for their specific applications.

The conventional model level to perform matching calculations has been for years the 1D approach. This approach presents advantages in term of physical description but has become rather timedemanding with the arrival of multistage boosting systems and HP/LP EGR circuits. To face the challenge of fast engine development processes, a new approach has therefore to be defined with a more appropriate balance between model complexity and CPU performance. 
Matching calculations are generally performed at an early stage of the engine development process when only little geometrical information is defined and no experimental data are available for the base engine. In these conditions, lookup tables or MVEM are not appropriate to simulate combustion processes and a predictive model is required with, as a minimum, a crank angle resolution in cylinders. 1D multizone models give a good description of in-cylinder heterogeneities involved in the local combustion and pollutant production terms [26]. However, as pollutant prediction is not essential for architecture matching, OD phenomenological models are preferred for their sufficient physical representative capability and reasonable CPU expenses [27]. To calculate the engine scavenging behavior and the exhaust temperature, 1D wave action model are particularly accurate. Nevertheless, they require for correct wave effects predictions the design information of the intake and exhaust systems (runner diameters, pipe lengths, etc.) and a precise description of their acoustic behavior. This information which can be measured in specific impulse test rigs [28] or extracted from 3D CFD models [29], is not available at an early engine development stage. So, 1D model capabilities cannot be fully exploited and the lower computational cost of OD FEM's become more attractive to reproduce the most important thermodynamics processes. For the different air path components such as turbochargers, intercooler, air filter, etc., large data bases with results of characterizations performed in specific test benches are generally provided. These data are in form of characteristics maps or lookup tables over wide operating ranges. MVM have therefore a sufficient complexity to model these different engine components.

From these considerations, it results that the adequate trade-off between maximum physical description and minimum computational cost to perform efficient matching calculations is a combination of OD phenomenological combustion model, with a OD FEM for the multi-cylinders and manifolds, and a MVM for the other air path elements. In that way, advantages of reasonable computational cost from the OD-FEM and MVM approaches are combined with the physical depth of detailed cycle resolved cylinder models.

In addition, matching objectives are generally defined in terms of engine performance with boost pressure targets. The variables of interest in matching calculations are the ones describing turbochargers behavior, position of turbine actuators, etc. Nonetheless, equations resolutions performed by typical matching codes such as wave action models use the actuators variables as an input data to predict engine performance (actuators oriented model). In that way, control strategies for each engine actuators need to be developed and a large number of iterations are required to reach given performance objectives controlling actuator positions. This approach is low efficient and time consuming for steady-state calculations. That's why a new resolution algorithm has to be defined to run the simulations in a straightforward manner, from engine performance objectives to charging system configuration (boost pressure oriented model). In transient operations, the gas path handle different relevant physical effects such as mass accumulation transport of species, inertias, etc. and control strategies have an important impact on the boosting system performance. In this case, a boost pressure oriented algorithm cannot be employed and the conventional actuators oriented scheme remains the most appropriate. To reduce as much as possible CPU expenses during matching calculations, the simulation model has therefore to integrate both approaches, boost pressure oriented model for steady state conditions and actuators oriented model for transient operations.

In this paper, a OD engine model especially developed for matching calculations will be described. First, the crank angle resolved model that regroups the combustion and the FEM will be introduced. Second, the intake and exhaust MVM will be presented with their different elements. An original representation of turbine performance is proposed for matching calculations. These models will be then interconnected to form a comprehensive engine model and both boost pressure and actuators 
oriented algorithms will be described. Finally, a complete validation process has been carried out to assess the new modeling approach. Comparisons between experimental and modeled data will be discussed in the last section.

\section{Matching Oriented Model}

The engine model proposed in this paper is a combination of FEM and MVM. Figure 1 shows a representation of the model components. The model core is a FEM of the engine cylinders, the intake and exhaust manifold and the HPEGR line with a cooler and a valve. The cylinders models include a diesel combustion model.

The basic engine model is connected to the air path model at intake and exhaust manifolds. Indeed, there are two different air path models depending on the type of calculations. For matching or boosting pressure oriented calculations the air path is represented by a MVM. In such calculations the input for the model is the boosting pressure (at the intake manifold inlet) and the output is the position of all the actuators allowing achieving this boosting pressure objective. For transient or control oriented calculations the air path model is also FEM in order to account for accumulation effects in the lines. In transient calculations the model inputs are the position of the actuators and the output would be the resulting boosting pressure and flow variables throughout the engine.

The whole model is coded in the Matlab environment. This allows using advanced algotithms to control the calculations for both matching and transient calculations.

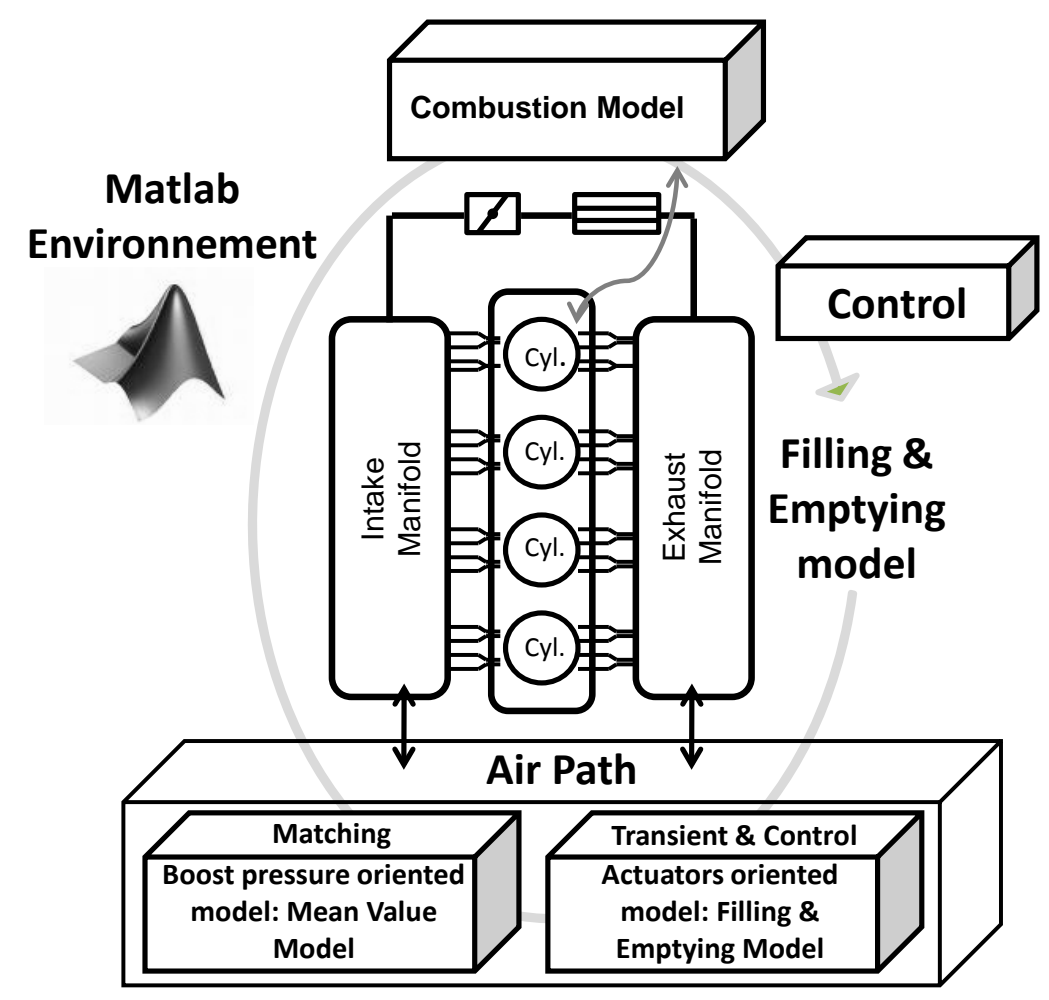

Figure 1. Elements of the proposed matching model

\subsection{Crank Angle Resolved OD Engine Model}

As explained above the engine cylinders and manifolds are calculated by FEM able to take into account mass fluctuations during the gas exchange. In Figure 1, a 4 cylinder engine is represented 
but the model is extendable to any number of cylinders. It is important to note that the HPEGR is included in the engine model since the flow is related with the instantaneous intake - exhaust pressure ratio.

Basically, the FEM used here is a collection of elements available in the code OpenWAM developed in the authors' lab. For the sake of simplicity these models will not described here, only each type of model will be pointed and some references to papers will be given. A detailed description of the models and even the source code can be retrieved at OpenWAM website [7].

The cylinders and manifolds are calculated as an open control volumen. An explicit crank angle resolved solution of continuity, energy and state equations is performed. The cylinder model includes the effect of combustion chamber deformations due to pressure and inertia forces as explained in [30]. The thermal flows and wall temperatures are calculated by a nodal approach [31]. Convection coefficient is calculated following Woschni [32] with some corrections for the effect of swirl proposed by Payri et al. in [33][34]. For a proper trapped mass calculation the effect of scavenging [35] and blow-by [30] are also considered. The gas properties are estimated as a mass weighted average between air, fuel $\left(\mathrm{C}_{10.8} \mathrm{H}_{18.7}\right)$ and stoichiometric burnt gas properties obtained from JANAF database [36] and revised by SANDIA laboratories [37].

The diesel combustion model used here is the one proposed by Arregle et al. [38][39]. The model constructed around a spray-mixing model is based on the gaseous steady jets theory and on the conceptual injection and combustion models proposed by Dec [40] and Hiroyasu [41]. This model evaluates the Apparent Combustion Time (ACT) the delay from the time when a given fraction of the fuel has been injected and the time when this fuel has burnt. It is possible to rely then the injection rate with the RoHR with only a calibration parameter to tune for a given engine. The model gives particularly good results for conventional mostly diffusive combustion, with low EGR rates and low swirl numbers. It also gives an estimate of NOx formation through the Zeldovich mechanism.

By the way, it is also possible to use "recorded" RoHR coming from testing campaigns. Typically they are processed as mathematical functions such as a combination of 4 Wiebe laws [42][43].

The flow between cylinders and manifolds is estimated using the adiabatic nozzle equation and depends on upstream (in) pressure and temperature and on downstream (out) pressure.

$$
\dot{m}=C_{d} A_{\text {ref }} p_{\text {in }} \sqrt{\frac{2 \gamma}{R(\gamma-1) T_{\text {in }}}} \sqrt{\left(\frac{P_{\text {out }}}{P_{\text {in }}}\right)^{\frac{2}{\gamma}}-\left(\frac{P_{\text {out }}}{P_{\text {in }}}\right)^{\frac{\gamma+1}{\gamma}}}
$$

For the poppet valves, the reference area Aref corresponds to the seat section while the discharge coefficient $\mathrm{Cd}$ is interpolated from the experimental data obtained in the flow test rig as a function of valve lifts and flow direction.

For the EGR valve, HP EGR rate XHPEGR appears generally as an objective in the matching calculations. The corresponding averaged mass flow passing through the HP EGR circuit depends of the breathing capability and is defined as:

$$
\widehat{\dot{m}}_{H P E G R}=\frac{X_{H P E G R}\left(\hat{\dot{m}}_{a i r}+\hat{\dot{m}}_{L P E G R}\right)}{1-X_{H P E G R}}
$$


where $\widehat{m}_{a}+\widehat{m}_{L P E G R}$ is the cycle-averaged mass flow rate entering in the intake manifold by the external section. The position of the HPEGR valve is thus readjusted during the simulations to obtain the desired mass flow applying to the effective section the following control:

$$
C_{d}^{\alpha+720^{\circ}} A_{\text {ref }}=\frac{X_{\text {HPEGR }}\left(\hat{\dot{m}}_{\text {air }}+\hat{\dot{m}}_{\text {LPEGR }}\right)}{1-X_{\text {HPEGR }}} \frac{C_{d}^{\alpha} A_{\text {ref }}}{\hat{\dot{m}}_{\text {HPEGR }}}
$$

Heat transfer is estimated by the effectiveness method in the HP EGR cooler and by the 1-node model with thermal resistance scheme [44] in the ports and manifolds. Different characteristics ducts are defined to reproduce the considered geometries and the same correlations presented for the exhaust line are employed for the exhaust manifold and all outer surfaces. For the other inner surfaces, heat transfer coefficients are calculated in the intake manifold and intake ports with the Nusselt-Reynolds correlation presented by Depcik and Assanis [45]:

$$
N u_{\text {inner }}=0.0694 \mathrm{Re}^{\frac{3}{4}}
$$

while the correlations introduced by Caton [46] and modified by Reyes [47] are used in the exhaust ports. In the exhaust ports, the turbulence generated at the cylinders discharge has an important impact on the heat transfer and a distinction is made when the exhaust vales are open or closed:

$$
N u_{\text {inner }_{\text {open }}}=0.5 \times 0.0075 \mathrm{Re}
$$

$$
N u_{\text {inner }_{\text {closed }}}=0.022 \widehat{\mathrm{R}^{0.8}}
$$

When the valves are closed, in addition to different correlation coefficients, a cycle-averaged Reynolds number Re is considered instead of the instantaneous value.

\subsection{Mean Value Based Gas-Path Description}

Multistage boosting architectures regroup a large number of configurations that needs highly flexible simulation tools to efficiently describe different engine assemblies. The intake and exhaust line models consist thus of individual components that can be assembled arbitrarily to build a complete description of the gas path. The main architectures having some similarities, basic structures are also proposed here to give a better overview of possible assemblies.

\subsubsection{Intake Line}

The base structure and the intake boosting components library can be observed in Figure 2. The air mass flow enters with atmospheric conditions in the air filter to exit in 1 where it undergoes a mixing process with the LP EGR mass flow to reach conditions in 1'. The evolutions in the LP and HP intake charging systems go from 1' to 12 and 12 ' to 2 respectively. Between both stages, an intercooler can perform a cooling process depending of the bypass valve control. After the HP stage, the mass flow passes through an aftercooler and a throttle valve to arrive in the intake manifold. The intake throttle is only used in combination with the HP EGR system when the pressure difference between the intake and exhaust manifold is not sufficient to obtain the desired HP EGR rate. For the LP and HP intake charging systems, the component library includes superchargers, centrifugal superchargers, eBoosters, centrifugal compressors in single or parallel configuration and connections for single boosting system. 


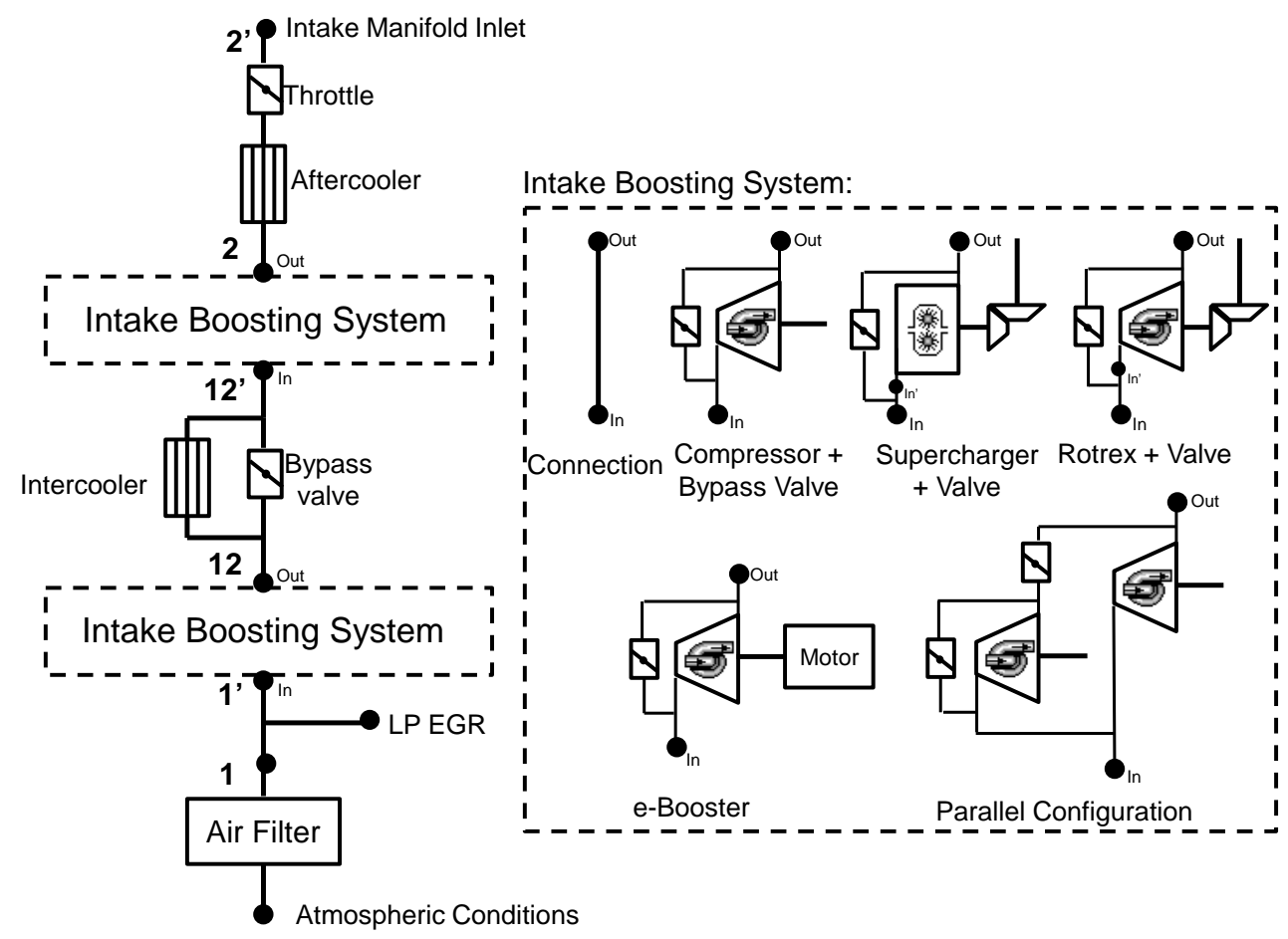

Figure 2. Based structure and components library of the intake line MVM.

In steady state operations, matching calculations are based on a boost pressure oriented resolution scheme. Engine performance objectives are defined in term of pressures in 2' and 12' corresponding to combustion and control requirements respectively. According to the boosting architectures, variations of P12' are generally simulated to optimize exhaust backpressure and fuel consumption. Volume capacities with mass accumulation are not considered and mass flows are assumed to be constant along the whole air path. Heat transfers are discarded between the components although models like the ones used for the exhaust line can be integrated if their effects are judged significant. The submodels used to calculate the different elements are briefly described below.

Engine breathing capability is reproduced by the FEM which gives to the MVM the mass flow at the intake manifold inlet. This mass flow is imposed constant from 1' to 2'. HP and LP EGR rates (X $\left.\mathrm{X}_{E G R}\right)$ are generally defined before matching calculations as combustion objectives to respect particular emissions regulations. LP EGR mass flow and, as a consequence air filter mass flow, are defined as:

$\dot{m}_{L P E G R}=\dot{m}_{1} X_{L P E G R}\left(1+\frac{X_{\text {HPEGR }}}{1-X_{H P E G R}}\right)$

$\dot{m}_{1}=\dot{m}_{1^{\prime}}-\dot{m}_{L P E G R}$

Air filters and coolers are characterized in a flow test rig where their pressure losses are measured as a function of corrected mass flow. Experimental data are accurately fitted with polynomial functions which are then directly integrated in the models. It is assumed the gas flow suffers an isothermal process in the air filter, whereas heat transfer in the coolers is calculated by the effectiveness $\varepsilon$ method which evaluates the outlet temperature as:

$T_{\text {out }}=T_{\text {in }}+\varepsilon\left(T_{\text {ext }}-T_{\text {in }}\right)$ 
where $T_{\text {ext }}$ stands for the external cooling fluid temperature and NTU the number of transfer units. If the coolers have not been characterized in a thermal flow rig, typical NTU values for heat exchangers can be found in [48].

Throttle and bypass valves are modeled as isentropic nozzles where the mass flow is expressed from the Saint Venant equation (Eq. 1)

From a control point of view the effective section in a valve is directly proportional to the actuators position. But here, with a boost pressure oriented resolution and knowing the mass flow, the throttle can be considered as a pressure drop to reach the HP EGR objectives and the effective section is calculated as a resultant. Bypass valves are generally used in on/off configurations. In this case, no pressure losses are considered across the valve.

The compressor model is based on the characteristic maps obtained in turbocharger test bench that give corrected shaft speed and efficiency as a function of corrected mass flow rate and pressure ratio. These maps are extrapolated in the low rpm zone with the isentropic enthalpy gain method [49] and interpolated in the model by polar basis functions. The compressor outlet temperature is derived from the isentropic efficiency.

The isentropic power used as turbocharger input data in the exhaust line MVM is expressed with the mass flow rate and total enthalpy changes. Taking into account a motor efficiency, this power corresponds for the eBooster to the electrical demand. If limitations are imposed by the vehicle electrical network, equations are inversed and the output power is calculated as a function of electrical power.

Superchargers are connected via a transmission to the engine crankshaft. The transmission ratio is an additional variable in the matching calculations and a mechanical efficiency depending on the running conditions is added to the compressor work. Superchargers models are also based on the measured characteristic maps but their interpolations can be performed in different ways according to the matching objectives. First, supercharger speed can be calculated as a function of corrected mass flow and pressure ratio to obtain the optimized transmission ratio. Then, considering a given transmission ratio, the pressure ratio can be expressed as a function of supercharger speed and corrected mass flow to give the outlet pressure:

\subsubsection{Exhaust Line}

The proposed base structure of the exhaust line MVM is shown in Figure 3 with its boosting components library. The gas mass flow determined by the FEM enters in 3 at the HP stage inlet. The evolutions in the HP and LP exhaust charging systems go respectively from 3 to 34 and 34' to 4 while heat losses between both stages are taken into account by a heat transfer model. At the LP stage outlet, the gas flow passes through the post treatment system (DOC + DPF) and the silencer before going out to the atmosphere. A LP EGR circuit composed by a valve and a cooler connects the DPF outlet to the air filter outlet. An additional EGR valve is fitted at the silencer inlet to increase the exhaust backpressure when the pressure difference is not sufficient to reach the desired LP EGR rate. For the HP and LP exhaust boosting systems, the components library includes wastegated fixed geometry turbines in single or parallel configuration, variable geometry turbines with possibility of additional wastegate valve and connections for single charging systems, superchargers or eBoosters. 
Keeping the same philosophy, volume capacities are not considered in steady state operations and mass flows as gas composition are assumed to be constant in the whole exhaust line. Eq. 3 is used to calculate the LP EGR valves position whereas a mass balance is introduced in point 45 to determine the silencer mass flow as a function of the LP EGR mass flow. Pressure losses across the LP EGR cooler, post treatment system and silencer are modeled by its steady pressure loss. Heat transfer is estimated by the effectiveness method in the EGR cooler while specific models as the ones proposed by Boger et al. [50] or Konstandopoulos et al. [51][52] can be employed for the DOC and DPF. The other submodels used in the exhaust line MVM are described below.

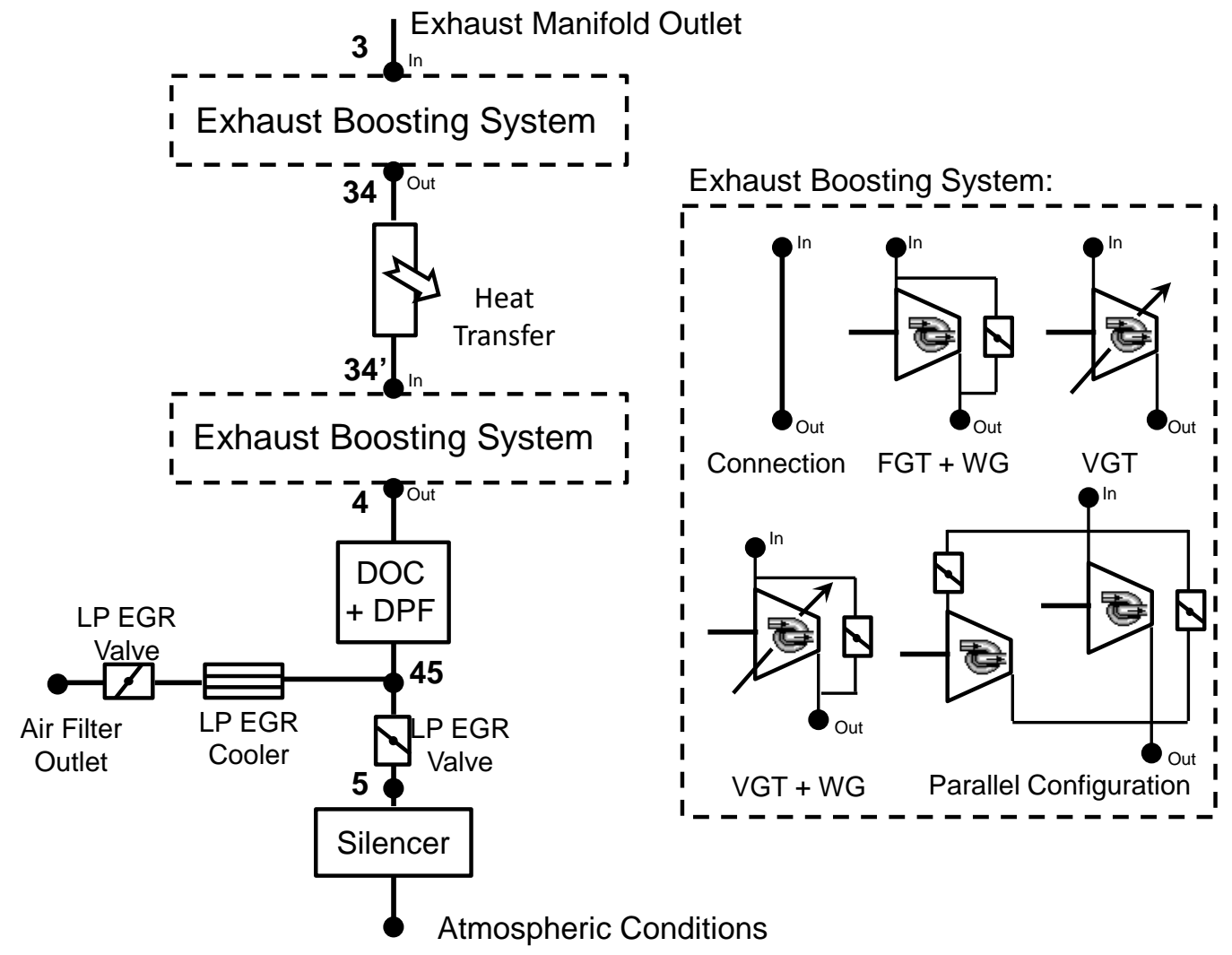

Figure 3. Based structure and components library of the exhaust line MVM.

The heat transfer model is based on the thermal resistance scheme already mentioned for the exhaust manifold [43] which computes the radial heat flux through one node at the inner side on the pipe wall. A duct with a characteristic length and diameter is defined to reproduce the considered air path geometry and equations are resolved in only one calculation points assuming constant heat transfer along the whole pipe. Convection heat transfer coefficients at the inner and outer surface are calculated by correlations presented by Depcik at al. [42] and Hilpert [53] respectively.

$N u_{\text {inner }}=0.0718 \mathrm{Re}^{\frac{3}{4}}$ and $N u_{\text {outer }}=0.193 \mathrm{Re}^{0.168} \operatorname{Pr}^{\frac{1}{3}}$

where $\mathrm{Nu}, \mathrm{Re}$ and $\mathrm{Pr}$ are the Nusselt, Reynolds and Prandtl number. The radiation heat transfer coefficient is derived from the Stefan-Boltzmann laws and the correlations proposed by Konstantinidis [54] are employed to estimate the emissivity of the different materials used in modern passenger cars engine design. The viscosities are obtained as a function of the temperature by the correlations proposed by Sutherland [55]. 


\subsubsection{Wastegated Fixed Geometry Turbine}

Turbine performance is usually modeled from steady characteristic maps that refer corrected mass flow and adiabatic efficiency as a function of expansion ratio. The problem of this representation is that the mass flow is corrected with the inlet temperature and pressure. This pressure is the result of its behavior and appears to be an unknown in the matching process. Nevertheless, the pressure downstream of the turbine, corresponding to the pressure losses of the entire exhaust line, is generally known at early development stage. Therefore the use of this pressure is more appropriate in the matching process and the adapted gas turbine flow can be introduced as:

$$
\dot{m}_{\text {adapt }}=\dot{m}_{\text {cor }} \Pi_{t}=\frac{\dot{m}_{t} \sqrt{\frac{T_{\text {in }}}{T_{\text {ref }}}}}{\frac{P_{\text {out }}}{P_{\text {ref }}}}
$$

where $P_{\text {out }}$ is the turbine outlet pressure and subindex ref stands for reference conditions. This parameter has the particularity of taking into account design parameters (exhaust manifold temperature and exhaust back pressure) remaining homogeneous to the turbine behavior.

A natural design factor in turbocharger calculation is the turbocharger power. The performance maps do not normally use this parameter but, keeping with the same philosophy as for the mass flow, the turbine corrected power can be expressed as:

$$
\dot{W}_{\text {cor }}=\dot{m}_{\text {cor }} C_{p t} \eta_{t} T_{\text {in }}\left(1-\Pi_{t}^{\frac{1-\gamma}{\gamma}}\right)=\frac{\dot{W}_{t} \sqrt{T_{\text {in }} / T_{\text {ref }}}}{\frac{P_{\text {in }}}{P_{\text {ref }}}}
$$

where $C_{p t}$ is the exhaust gas specific heat at constant pressure and the $\eta_{t}$ is the turbine isentropic efficiency. The adapted power is then defined as:

$$
\dot{W}_{\text {adapt }}=\dot{W}_{\text {cor }} \Pi_{t}=\frac{\dot{W}_{t}}{\sqrt{T_{\text {ref }} / T_{\text {in }} \frac{P_{\text {out }}}{P_{\text {ref }}}}}
$$

Turbine performance expressed with turbine adapted mass flow and adapted power is presented in Figure 4. All the measured points collapse in a single quadratic curve and thus, easy to interpolate. It has been proved that this representation is quite robust [56]. In the figure, the adapted curve obtained from data measured on a gas-stand is compared to points measured on-engine at different speed and load. 


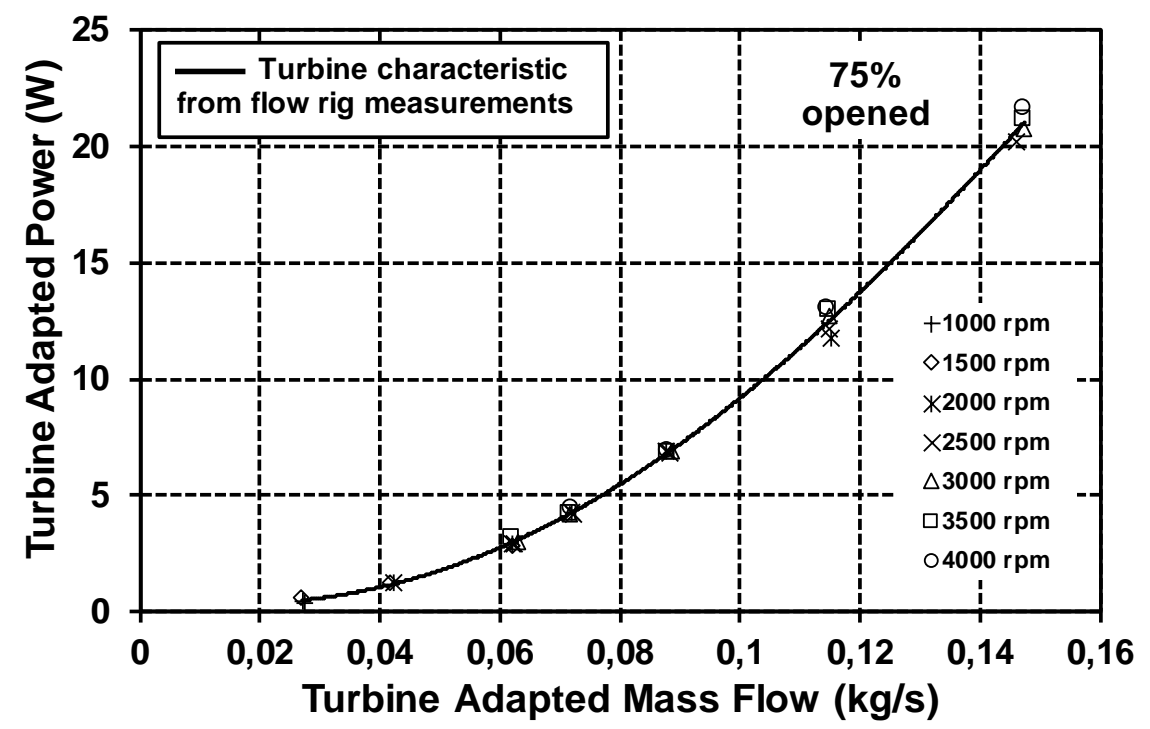

Figure 4. On-engine adapted turbine power for different engine speeds and loads vs turbine characteristics measured in a steady gas-stand.

In steady state operations, turbine power $\dot{W}_{t}$ is equal to the compressor power calculated by the intake line MVM. The characteristic maps can therefore be interpolated with quadratic functions to obtain adapted mass flow and pressure ratio as a function of adapted power. Knowing the adapted mass flow passing through the turbine, the real mass flow for both turbines and wastegate can be calculated as:

$\dot{m}_{t}=\frac{\dot{m}_{\text {adapt }} \frac{P_{\text {out }}}{P_{r e f}}}{\sqrt{\frac{T_{\text {in }}}{T_{r e f}}}} \quad \dot{m}_{W G}=\dot{m}-\dot{m}_{t}$

and the wastegate actuator position can be deduced from Eq. 12. The turbine efficiency is then derived from the isentropic power as:

$\eta_{t}=\frac{\dot{W}_{t}}{\dot{m}_{t} C_{p t} T_{i n}\left(1-\Pi_{t}^{\frac{1-\gamma}{\gamma}}\right)}$

Finally assuming that heat losses are small enough to be neglected in the wastegate, a temperature balance is performed at the turbine outlet as follows:

$T_{\text {out }}=\frac{\dot{m}_{t} T_{t_{\text {out }}}+\dot{m}_{W G} T_{\text {in }}}{\dot{m}}$ with 
$T_{t_{\text {out }}}=T_{\text {in }}-T_{\text {in }} \eta_{t}\left(1-\left(\frac{P_{\text {in }}}{P_{\text {out }}}\right)^{\frac{1-\gamma}{\gamma}}\right)$

\subsubsection{Variable Geometry Turbine (VGT)}

In a variable geometry turbine, the full exhaust gas mass flow is routed via the turbine and the vanes position is controlled to produce the desired power. The representation of Adapted Power vs Adapted Mass Flow is as represented in Figure 5 and each measured VGT position yields to a single operating line. The operative range of the turbine is limited by the closest and most open position lines. In this area it is possible to draw constant expansion ratio curves plotted in the figure in light gray color.

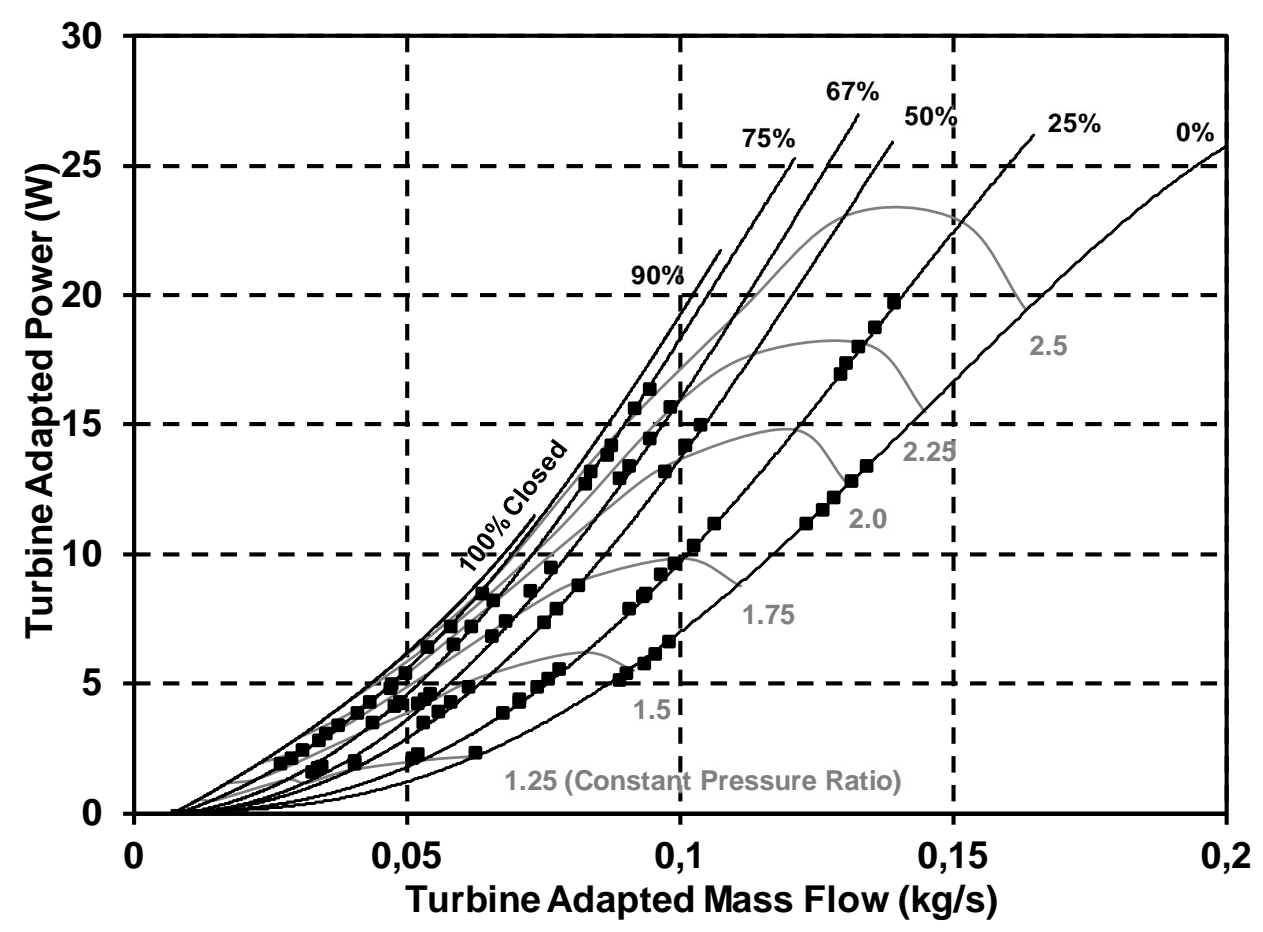

Figure 5. Adapted performance map of a VGT.

By interpolation of the turbine adapted characteristic maps, the actuator position and pressure ratio can be obtained as a function of adapted mass flow and adapted power as:

$\chi_{t}, \frac{P_{\text {in }}}{P_{\text {out }}}=f\left\{\dot{m}_{\text {adapt }}, \dot{W}_{\text {adapt }}\right\}$ and $\dot{m}_{\text {adapt }}=\frac{\dot{m} \sqrt{\frac{T_{\text {in }}}{T_{\text {ref }}}}}{\frac{P_{\text {out }}}{\mathrm{P}_{\text {ref }}}}$

If $\chi_{\mathrm{t}}$ is higher than the most open position, an additional wastegate is fitted around the VGT and equations are resolved as a FGT having the same swallowing capacity than the fully open VGT. 


\subsection{Control Strategy}

The resolution methodology corresponding to the boost pressure oriented scheme is presented in Figure 6. From initial values and test campaign data, a first air mass flow is estimated to run the intake line model. In this model, several variables are defined as a function of temperature or corrected parameters. Since important variations of these parameters have only small consequences on the calculated variables, two or three loops are generally required to obtain the convergence of the thermodynamics properties along the whole air path. At the end, the compressors power and the aftercooler outlet temperature are respectively transferred to the exhaust MVM and FEM.

Numerous injection strategies can be implemented with the combustion model to determine or adjust the injection settings according to specific objectives. In matching calculations, the fuel mass injected per cycle is generally defined as a function of AFR, while the injection timings are calibrated to achieve the best fuel consumption under limited maximum cylinder pressures. When the combustion model is called, an iterative process is thus performed to optimize the injection timings as a function of the combustion results obtained. The optimum injection law and the RoHR are then sent to the cylinders models.

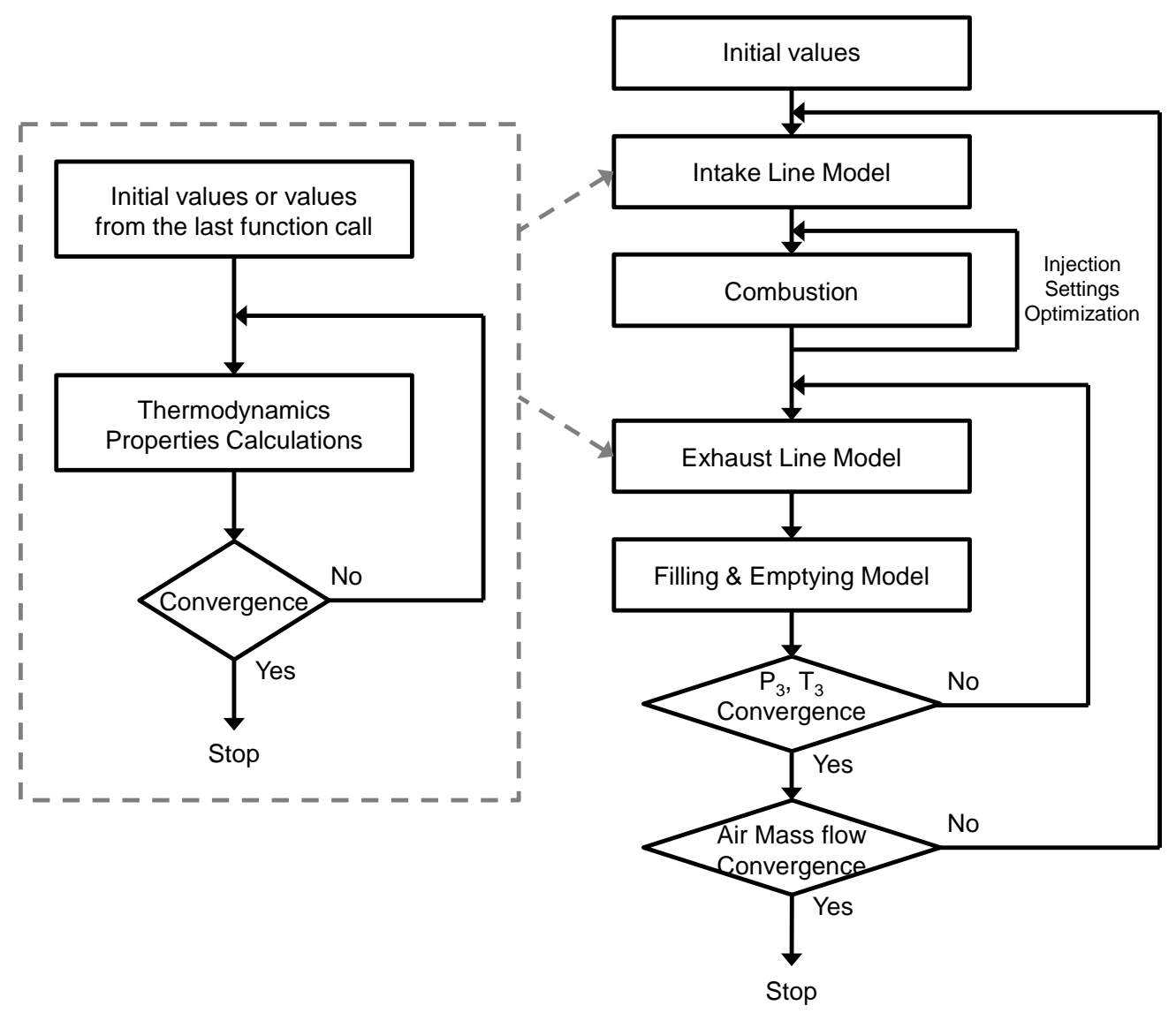

Figure 6. Boost pressure oriented resolution scheme.

With compressors power coming from the intake MVM and an estimated exhaust manifold temperature, the exhaust MVM calculates the thermodynamics properties along the exhaust line and provides the corresponding exhaust manifold pressure to the FEM. As for the intake MVM, 2 or 3 iterations must be carried out to achieve a complete convergence of all thermodynamics properties. Knowing the RoHR and the mean pressures in manifolds, the FEM is resolved as shown in Figure 7. 
At each time step, the mass flows through the poppet valves, the EGR valve and the external sections are first evaluated from the pressure and temperature values obtained in the previous time step. If the new mass flows are significantly different to the previous ones, the resolution time step is reduced from the 0.5 cad reference to a smaller one until fulfilling a calibrated stability criterion. With the new mass flows, heat transfers and thermodynamic properties are then updated in the manifolds. Finally the specific submodels such as blow-by, fuel injection, scavenging model, etc. are evaluated to calculate the new thermodynamics properties in the cylinders. When an engine cycle has been calculated, the instantaneous averaged manifolds pressure is compared to the mean value ones and if necessary the external sections of the manifolds are corrected before running an additional cycle. Usually, in 3 or 4 engine cycles stability is reached in the different volumes and the mean values coincide with the instantaneous averaged ones. Nevertheless under high HP EGR rates, more engine cycles are normally required due to the instabilities that create the interactions between the HP EGR valve control and the external sections corrections.

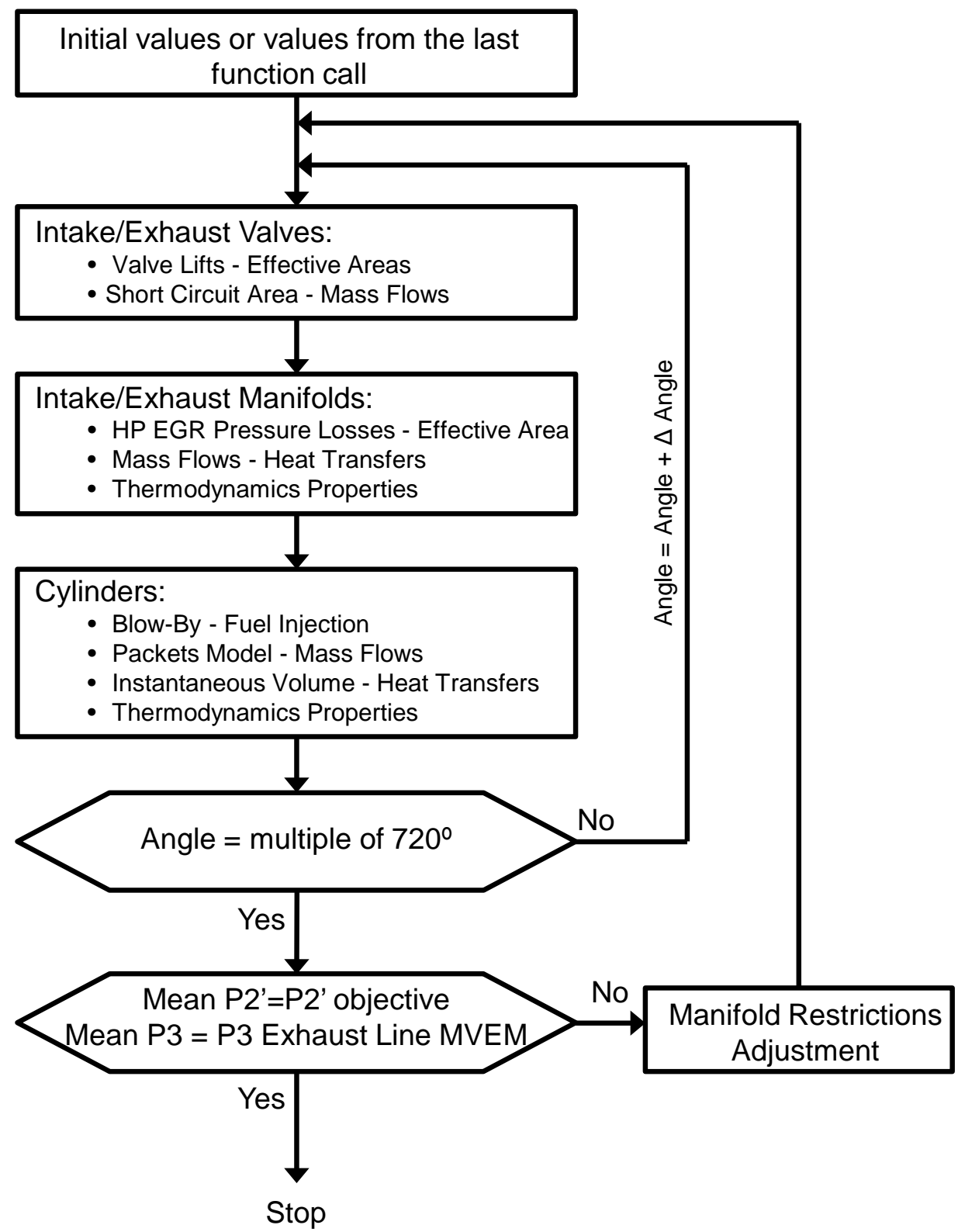

Figure 7. Resolution scheme of the FEM. 
In the end, the instantaneous exhaust manifold temperature is averaged to update the exhaust MVM and 2 or 3 iterations are carried out between both models to obtain convergence of the mean values in the exhaust manifold. Then, from the FEM results, intake line input data MVM and combustion models are updated and the whole resolution scheme is repeated until the mass flow passing through the intake external section corresponds to the previous calculated one. The overall model convergence is generally obtained in 2 or 3 iterations which represents about one minute of simulation in a regular personal computer (Intel Pentium $4 \mathrm{CPU} 2.8 \mathrm{GHz}$ ). This number of iterations and the corresponding computational time can obviously increase if a demanding injection setting optimization process is required or if the intake throttle has to be controlled to reach the desired HP EGR rate. Conversely, the simulation time can also be reduced as there is still some scope to further optimize the code (e.g. model simplification and solver speed up).

\section{Actuator Oriented Model and Control}

In the actuator oriented model, the FEM is extended to the Air Path to take into account the effects of mass accumulation and species transport. As shown in Figure 8, the different volumes present in the intake and exhaust lines are modeled with characteristic capacities where mass and energy conservation equations are resolved. Heat transfer is calculated using the same Nusselt-based correlations as the ones described for the manifolds while thermal capacities are added in all heat transfer models (cylinder, port, manifolds, etc.) to simulate thermal inertia effects. During the convergence to the initial operating conditions, a strategy disables these thermal capacities to speed up the calculations. Mechanical inertial effects are also considered with inertial shafts for the turbochargers. 


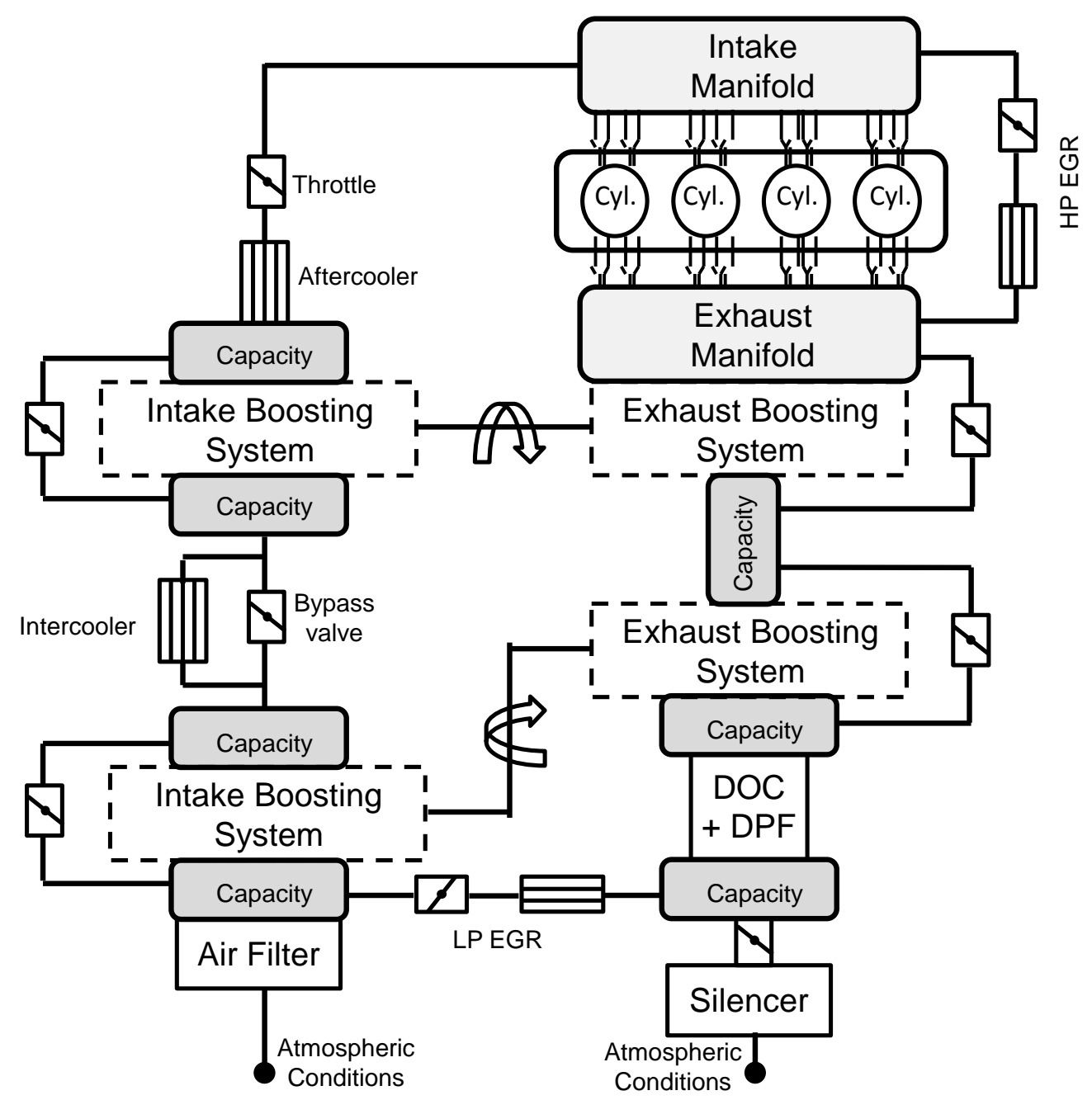

Figure 8. Actuators oriented air path model

The resolution of this model structure is based on actuators positions. Control strategies are therefore developed according to the transient test cycle to manage the engine dynamic and obtain the desired response. These strategies can be provided by a Simulink environment coming from ECU developments or be directly implemented in the model through Matlab functions. The FEM corresponding to the base engine has the same resolution scheme as one described for the boost pressure oriented model explained in the previous section. The only differences stand in the external manifold sections which are always maintained constant and in the HP EGR valve position which is determined by a control strategy (PID controller). However for the MVEM's, most of equations are inversed.

For the centrifugal compressors, corrected mass flow and efficiency are here calculated as a function of corrected shaft speed and compression ratio. Whereas for the turbines, adapted mass flow and adapted power are determined as a function of actuator position and pressure ratio. The relation between compressor and turbine powers is given by the shaft speed dynamic equation.

Valves, throttles and wastegates are directly solved by Eq. 1 with effective sections defined by control strategies. Finally for the other elements such as air filter, coolers, DOC+DPF, etc. flow test rig characteristics are reversed to obtain corrected mass flows as a function of pressure drops. In that way at each time step, mass transfers are first evaluated in all air path components to then update the thermodynamic properties in the reservoirs. MVM's are called each time a cylinder arrives at 
EVO. This fixed time step has been chosen in order to average the instantaneous manifold properties under the minimum periodic interval (at each manifold pulsation - 180 cad for a 4-cylinder engine).

\section{Model Validation}

Three different engines have been used to validate the model. Engine $A$ and $B$ are $2 \mathrm{I}$. diesel engine with single stage turbocharger and HP EGR from two different manufacturers. Engine $\mathrm{C}$ is a $2.2 \mathrm{I}$. diesel engine with parallel sequential turbocharging and HP EGR.

Motored tests have been carried out to tune the Woschni equation coefficients and deformation parameter. Then firing tests in the entire engine operative range (speed, bmep), including some points with EGR, have been carried out. The RoHR has been obtained by means of the combustion diagnosis tool CALMEC [57], which is virtually the reverse to our cylinder model. Some results in terms of RoHR and in-cylinder pressure peak are given in Figure 9. The errors in terms IMEP and incylinder maximum pressure fall within $\pm 2 \%$ for all the operating points and for the three engines.

The error in other mean variables at intake and at exhaust lines are plotted in Figure 10. The error at the intake is within $\pm 2 \%$, while at the exhaust is within $\pm 5 \%$. This is reasonable since the boosting pressure is imposed and all the errors accumulate in the prediction of turbine inlet pressure.

Figure 11 shows some instantaneous pressure results at cylinder and exhaust and intake manifolds. Even though the wave effects have not been calculated, the prediction of the intake and exhaust pulsation and consequently, the cylinder gas exchange is very well caught at lower speeds. At the highest speed (4500 rpm) there are some discrepancies both at intake and exhaust manifolds.
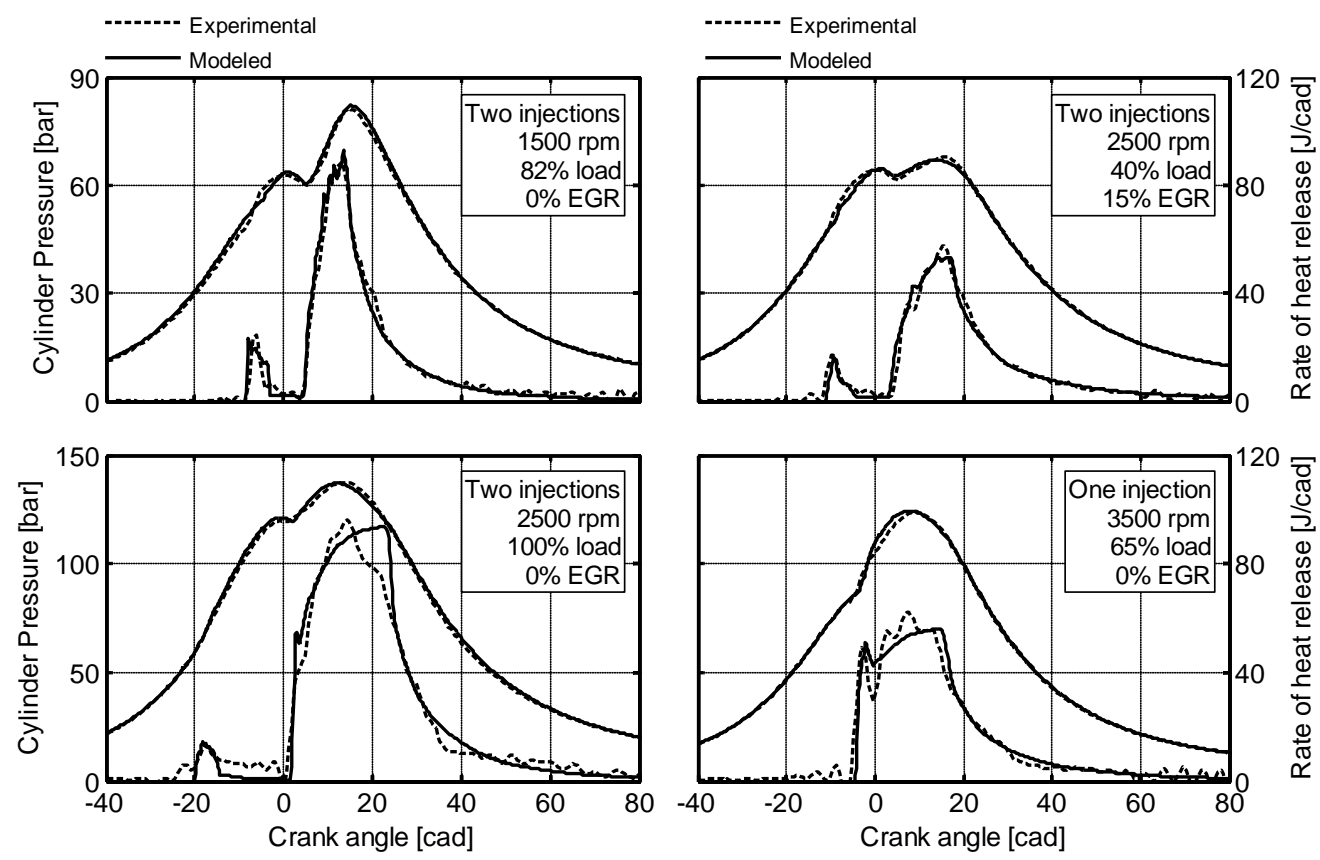

Figure 9. Cylinder pressure and RoHR for different operating conditions (Engine A) - Comparison between experimental and simulated evolution. 

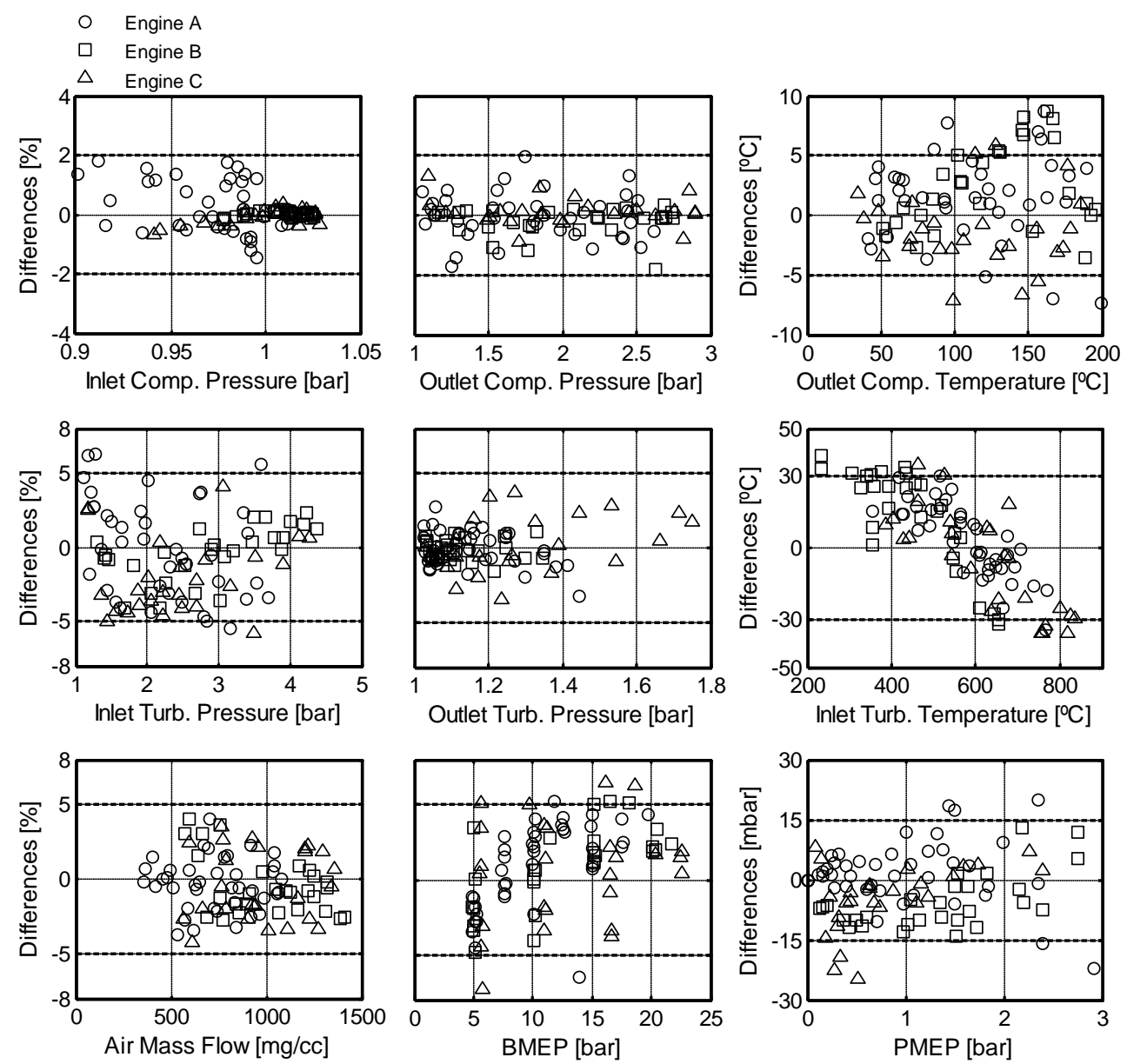

Figure 10. Comparison of experimental data and engine model prediction for all the operating conditions. 

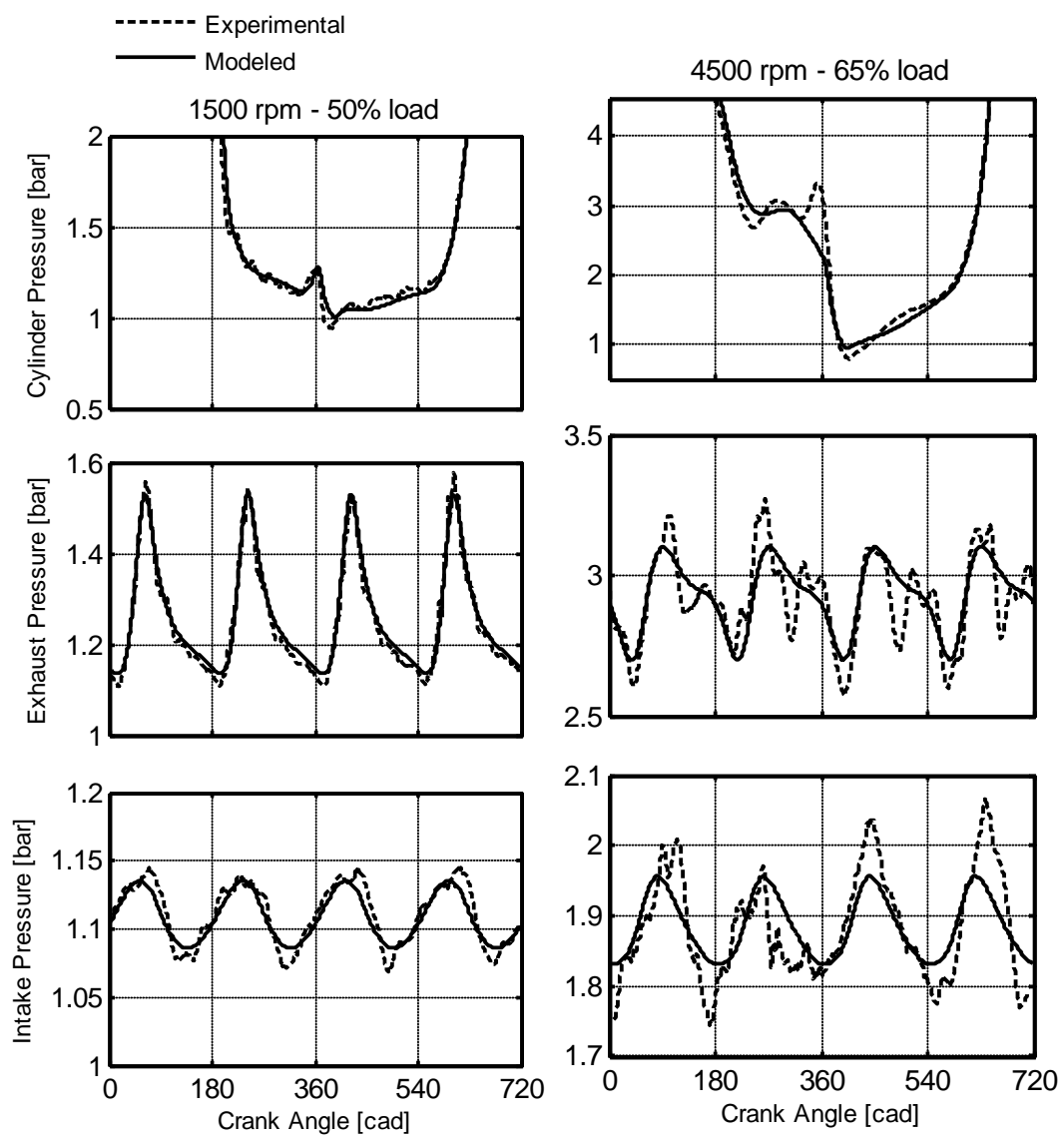

Figure 11. Instantaneous pressure at the cylinders (top), exhaust (middle) and intake (bottom) at 1500 (left) and 4500 (right) rpm for engine $A$.

The reason for the good prediction at low speed is that, given the small length of the compact exhaust manifold typically used in turbocharged diesel engines in order to keep the exhaust gas energy, the pressure pulsations wavelength is much longer. Beyond $3500 \mathrm{rpm}$ it is not the case and wave effects are more prominent. In the intake side the problem is slightly different. Turbo-charged diesel engines have not usually a tuned intake line, and if so, it is done at low speeds in order to improve there where the compressor cannot boost the engine properly. Engine $A$ in the figure is not tuned and so the prediction at low speed is good. At high speed, wave effects appear for the same reason than in the exhaust.

Summarizing, with compact exhaust manifolds the FEM provides quite good results (at least similar to 1D models) at low and medium engine speeds, up to $3500 \mathrm{rpm}$. If the intake line is not tuned, the prediction of the volumetric efficiency would be good in the same engine speed range. If the intake line is tuned, the FEM cannot calculate properly intake pressure pulsations. In this case a "tuning" parameter has to be used to account for the increased volumetric efficiency at the resonance speed.

A final assessment is presented in Figure 12 showing the comparison of the model with a transient test consisting in a tip-out test. Starting from full load, the pedal is suddenly released during some seconds and then suddenly pushed again to the full load. Turbo related variables have some delay because thermal and mechanical inertias. The model is able to catch these delays. 


\section{Application to an engine case}

In this section, an example of the use of the model is given. The goal is the definition of the boosting and EGR systems architectures with given objectives for maximum torque curve and EGR at partial and at full load. Compared to a previous engine version, the maximum torque is increased by $30 \%$ and the speed for the maximum torque and power points is also reduced to 1250 and $3500 \mathrm{rpm}$. It is quite the typical case of downspeeded nowadays. This is a case in which the benefits of using this model are particularly relevant. First, there is not much information of the engine because it is at an early development phase. Second, there are multiple boosting and EGR architectures to be considered. Third, it is a downspeeded engine so that the wave effects at the exhaust manifold are less critical.

Some results of intensive parametric studies carried out with the matching model are presented in the next figures. For instance, Figure 13 shows the results of a parametric study for different EGR rates and repartition between LP and HP EGR. In the figure a single operating point is considered 1750 rpm for a given turbocharger. The bottom plots in the figure show the efficiency of the charge air cooler and the brake specific mean consumption. The red lines in the maps correspond to the operative points where the compressor outlet temperature is equal to $190^{\circ} \mathrm{C}$, which is the limit for this turbocharger. The part of the maps above the red lines would be inaccessible. The horizontal colored bar in the bottom part of the maps stands for the results for HP EGR only but with an EGR cooler double size. The top plots in the figure are the calculated points over the compressor and turbine maps. The turbine map representation allows assessing visually if the chosen turbine is well matched for the application.
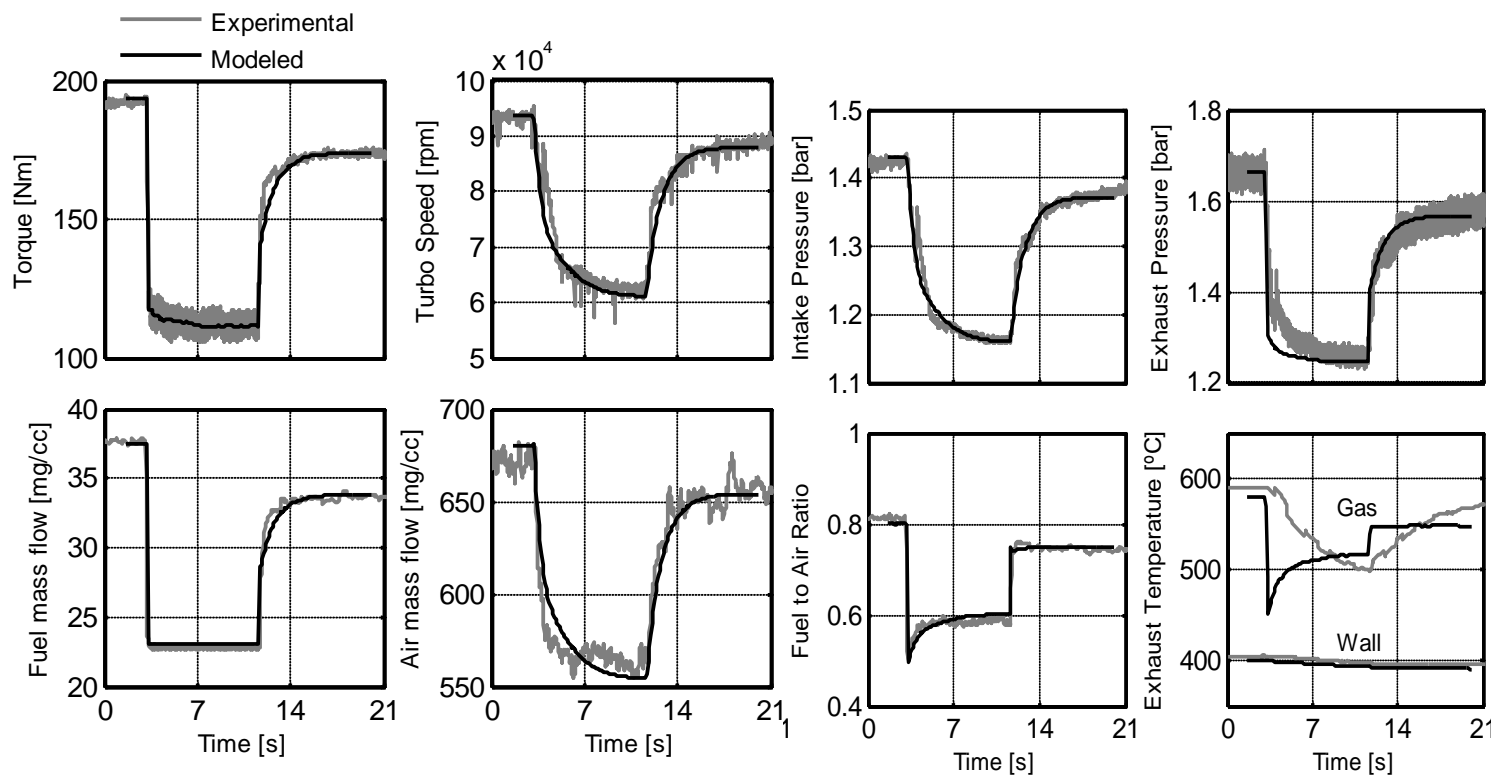

Figure 12. Comparison of simulation results with experimental data during a hot tip-out test performed at $1250 \mathrm{rpm}$ on Engine $C$. 

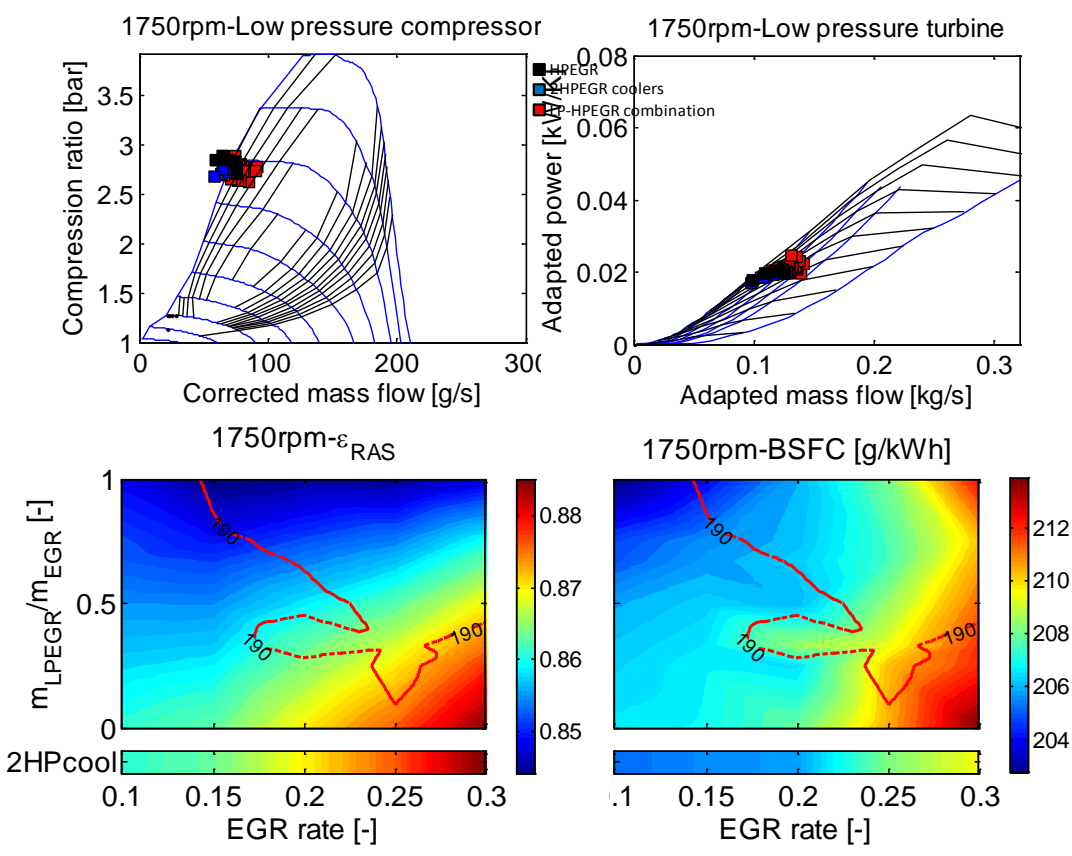

Figure 13. Compressor and turbine maps (top), maps of CAC efficiency and bsfc as a function of EGR rate ( $x$ axis) and LPEGR/EGR (y axis).

Figure 14 shows further results dealing with the effect of the EGR cooling system architecture and size. This issue may affect the matching. In the figure the consumption with different cooling systems is plotted: only one LP cooler, two LP coolers, 2 HP + one LP coolers, double size charge air cooler + $1 \mathrm{LP}$ cooler and only one LP cooler but with coolant at $50^{\circ} \mathrm{C}$. The results show that is more efficient to put more cooling power into the charge air cooler. Also, at this operating point it is more efficient to have both LP and HP EGR.

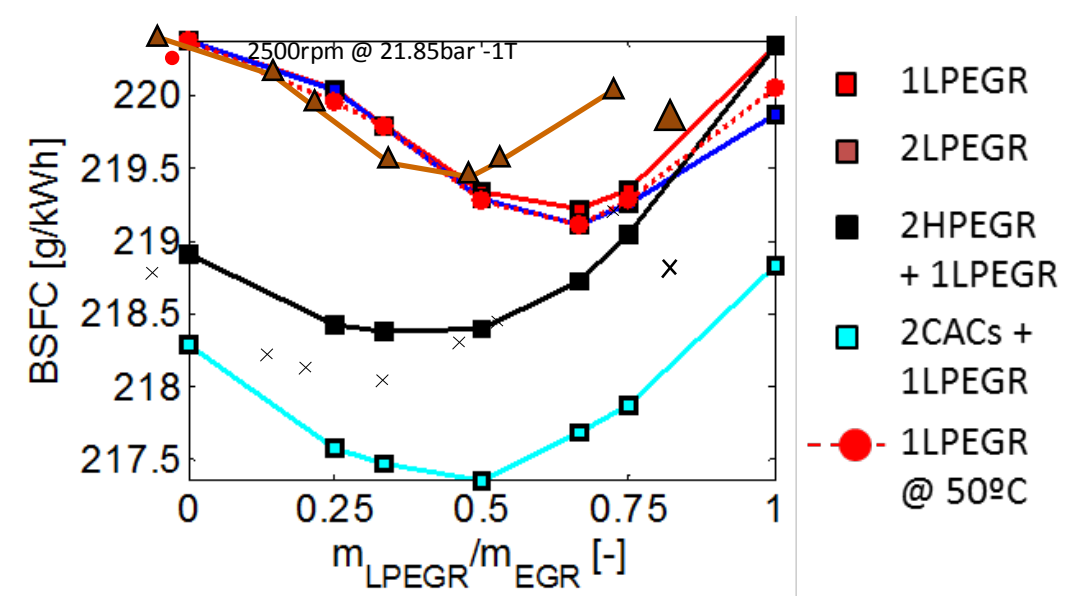

Figure 14. Specific fuel consumption with different cooling technologies as a function of the ratio between HP \& LP EGR.

These results are just an example with a few variables involved. Think in a more complete study with say 14 operating points, 7 LP/HP EGR repartition, 4 EGR levels, 5 different turbochargers and 5 different cooling alternatives. This makes 9800 calculations that are unaffordable with regular 1D modeling in a reasonable time. Furthermore, the accuracy can be quite similar if wave effects are not prominent, as it is usually in modern downspeeded turbocharged diesel engines. 
A final result is plotted in Figure 15 corresponding to transient prediction in a load step at fixed low engine speed $1000 \mathrm{rpm}$. In this case four different technologies are compared: single VGT with an old technology, single modern VGT, 2-stage with two FGT and finally 2-stage with a VGT in the LP. The numbers in the plot correspond to the time to arrive to $90 \%$ of the steady torque. The model is able to position the different technologies in terms of fun-to-drive.

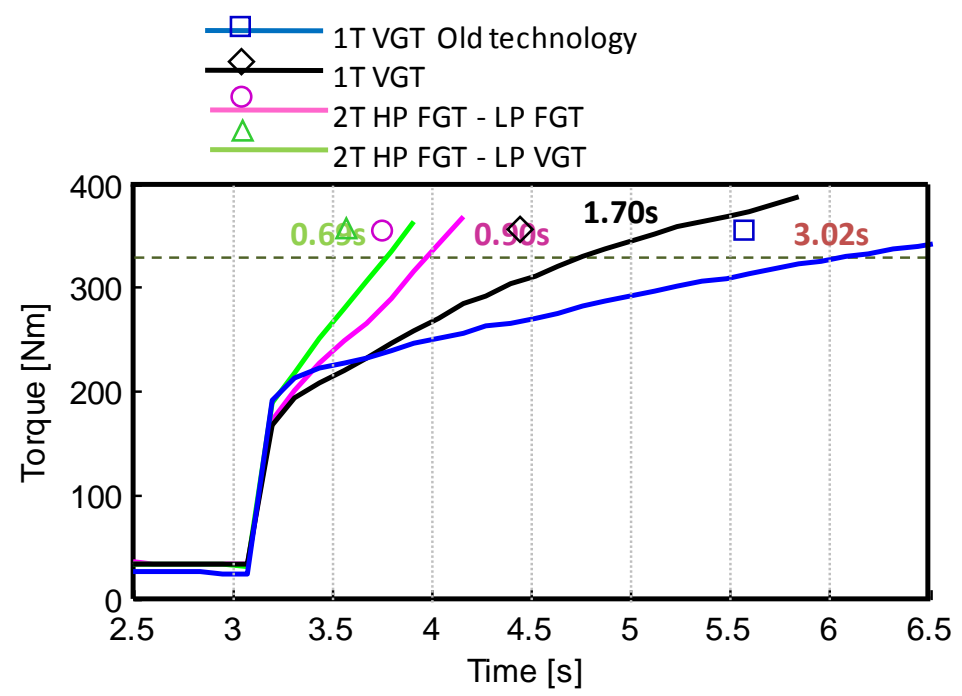

Figure 15. Torque response at $1000 \mathrm{rpm}$ in a tip-in test for different boosting technologies.

\section{Summary/Conclusions}

In the paper the use of FEM and MVM for matching of complex boosting and EGR architectures is fostered. The model proposed here is based on a FEM model of the cylinders and manifolds. In a first version of the model aimed to be used for matching purposes, the air path is calculated with a simple MVM where the intake and exhaust lines elements are calculated by steady relationships. A new representation for the turbine is proposed so that the matching procedure is straightforward since it is not needed to know beforehand the turbine inlet pressure. A control algorithm has been developed to launch the FEM engine model and the MVM air path model looking for the actuators positions needed to attain a given boosting pressure and LP/HP EGR objectives. At the same time the model watches that some thermo-mechanical limits (in-cylinder pressure, compressor outlet temperature, exhaust manifold pressure and temperature) are not exceeded.

In a second version of the model, the air path is also calculated as FEM by including some volumes in the intake and exhaust lines to account for accumulation effects. The model is predictive so that it calculates the flow properties as a function of time for a given position in the engine actuators.

The model has been validated with three different engines at numerous operating conditions including transient tests. The comparison between tests and model results show that the accuracy is similar to 1D calculations in certain conditions. The most important is that wave effects are not important. This can be true for engines with compact manifolds at low and medium speed.

In the paper an example of the use of the model has been presented. The model has been used to find the best boosting and EGR architectures to fulfill given torque and EGR objectives together with some thermo-mechanical constrains. The model has allowed to choose the boosting architecture, choice of turbochargers, definition of EGR system including coolers size, LP/HP EGR repartition and the results in fun to drive in a time frame at least ten times lower than a 1D code. 


\section{References}

1. A. Albrecht, O. Grondin, F. Le Berr, and G. Le Soliec. "Towards a Stronger Simulation Support for Engine Control Design: a Methodological Point of View". Oil \& Gas Science and Technology, Revue IFP, Vol. 62, No. 4, pp. 437-456, 2007, doi: 10.2516/ogst:2007039.

2. P. Gautier, A. Albrecht, P. Moulin, A. Chasse, L. Fontvieille, A. Guinois, and L. Doleac. "A New Simulation Step Towards Virtual Bench Through the Challenging Case of Two-Stage Turbocharger Diesel Engine Control Design". SAE Technical Paper 2008-01-0355, 2008.

3. A. Chow and M.L. Wyszynski. "Thermodynamic Modelling of Complete Engine Systems - A Review". Proceedings of the Institution of Mechanical Engineers, Part D: Journal of Automobile Engineering, Vol. 213, No. 4, pp. 403-415, 1999.

4. O. Grondin, R. Stobart, H. Chafouk, and J. Maquet. "Modelling the Compression Ignition Engine for Control - Review and Future Trends". SAE Technical Paper 2004-01-0423, 2004.

5. C.D. Rakopoulos and E.G. Giakoumis. "Review of Thermodynamic Diesel Engine Simulations under Transient Operating Conditions". SAE Technical Paper 2006-01-0884, 2006.

6. J. Bohbot, A. Lafossas, A. Albrecht, M. Miche, M. Chraibi, and A. Menegazzi. A New Coupling Approach Using a 1D System Simulation Software and a 3D Combustion Code Applied to Transient Engine Operation". SAE Technical Paper 2004-01-3002, 2004.

7. OpenWAM open source project website. http://www.openwam.org.

8. J. Galindo, J.R. Serrano, F. Arnau, and P. Piqueras. "Description and Analysis of a OneDimensional Gas-Dynamic Model with Independent Time Discretization". Proceedings of the ASME Internal Combustion Engine Division, Spring Technical Conference, Chicago, 2008.

9. F. Payri, J. Galindo, J.R. Serrano, and F.J. Arnau. "Analysis of Numerical Methods to Solve One Dimensional Fluid-Dynamic Governing Equations Under Impulsive Flow in Tapered Ducts". International Journal of Mechanical Science, Vol. 46, pp. 981-1004, 2004.

10. D.E. Winterbone and M. Yoshitomi. "The Accuracy of Calculating Wave Action in Engine Intake Manifolds". SAE Technical Paper 900677, 1990.

11. D.E. Winterbone, C. Thiruarooran, and A. Wellstead. "A Wholly Dynamical Model of a Turbocharged Diesel Engine for Transfer Function Evaluation". SAE Technical Paper 770124, 1977.

12. N. Watson. "Transient Performance Simulation and Analysis of Turbocharged Diesel Engines". SAE Technical Paper 810338, 1981.

13. N. Watson and M. Marzouk. "A Non-Linear Digital Simulation and Analysis of Turbocharged Diesel Engines under Transient Conditions". SAE Technical Paper 770123, 1977.

14. M. Kao and J.J. Moskwa. "Nonlinear Cylinder and Intake Manifold Pressure Observer for Engine Control and Diagnostics". SAE Technical Paper 940375, 1994.

15. Y.H. Zweiri, J.F. Winterbone, and L.D. Seneviratne. "Detailed Analytical Model of a SingleCylinder Diesel Engine in the Crank-Angle Domain". Proceedings of the Institution of Mechanical Engineers Part D: Journal of Automobile Engineering, Vol. 215, pp. 1197-1216, 2001.

16. L. Eriksson. "Modeling and Control of Turbocharged SI and DI Engines". Oil \& Gas Science and Technology - Revue IFP, Vol. 62, No. 4, pp. 523-538, 2007.

17. L. Guzzella and C.H. Onder. "Introduction to Modeling and Control of Internal Combustion Engine Systems". Springer-Verlag Berlin Heidelberg, ISBN 970-3-642-10774-0, 2010.

18. M. Jankovic, M. Jankovik, and I. Kolmanovsky. "Constructive Lyapunov Control Design for Turbocharged Diesel Engines". IEEE Transactions on Control Systems Technology, Vol. 8, No.2, pp.288-299, 2000.

19. E. Hendricks. "The Analysis of Mean Value Engine Models". SAE Technical Paper 890563, 1989.

20. E. Hendricks, A. Chevalier, M. Jensen, S.C. Sorenson, D. Trumpy, and J. Asik. "Modelling of the Intake Manifold Filling Dynamics". SAE Technical Paper 960037, 1996. 
21. J.P. Jensen, A.F. Kristensen, S.C. Sorenson, and N. Houback. "Mean Value Modelling of Small Turbocharged Diesel Engine". SAE Technical Paper 910070, 1991.

22. Y. He and C.C. Lin. "Development and Validation of a Mean Value Engine Model for Integrated Engine and Control System Simulation". SAE Technical Paper 2007-01-1304, 2007.

23. Y. He and C.J. Rutland. "Application of Artificial Neural Networks in Engine Modeling". International of Engine Research, Vol. 5, No. 4, pp. 281-296, 2004.

24. Y. He and C. Rutland. "Application of Artificial Neural Networks for Integration of Advanced Engine Simulation Methods". ASME ICE Division Fall 2000 Technical Meeting, Peoria, Illinois, 2000.

25. S. Pischinger, S. Schernus, G. Lutkenmeyer, H.J. Theuerkauf, T. Winsel, and M. Ayeb. "Investigation of Predictive Models for Application in Engine Cold Start Behavior". SAE Technical Paper 2004-01-0994, 2004.

26. D.T. Hountalas, D.A. Kouremenos, G.C. Mavropoulos, K.B. Binder, and Schwarz V. "Multi-Zone Combustion Modelling as a Tool for DI Diesel Engine Development - Application for the Effect of Injection Pressure". SAE Technical Paper 2004-01-0115, 2004.

27. J. Arregle, J.J. Lopez, J. Martin, and E. Mocholi. "Development of a Mixing and Combustion ZeroDimensional Model for Diesel Engines". SAE Technical Paper 2006-01-1382, 2006, doi: 10.4271/2006-01-1382.

28. A.J. Torregrosa, J. Galindo, C. Guardiola, and O. Varnier. "Combined Experimental and Modeling Methodology for Intake Line Evaluation in Turbocharged Diesel Engines". International Journal of Automotive Technology, Vol. 12, No.3, pp. 359-367, 2011.

29. J. Park, K.S. Lee, S. Song, and K.M. Chun. Numerical Study of a Light-Duty Diesel Engine with a Dual-Loop EGR System Under Frequent Engine Operating Conditions Using the DOE Method". International Journal of Automotive Technology, Vol. 11, No. 5, pp. 616-623, 2010.

30. F. Payri, S. Molina, J. Martin, and O. Armas. influence of Measurement Errors and Estimated Parameters on Combustion Diagnostic". Applied Thermal Engineering, Vol. 26, pp. 226-236, 2006.

31. A. Torregrosa, P. Olmeda, B. Degraeuwe, and M. Reyes. "A Concise Wall Temperature Model for DI Diesel Engines". Applied Thermal Engineering, Vol. 26, pp.1320-1327, 2006.

32. G. Woschni. "A Universally Applicable Equation for the Instanatenous Heat Transfer Coe_cient in the Internal Combustion Engine". SAE Technical Paper 670931, 1967.

33. F. Payri, X Margot, A. Gil, and J. Martin. Computational Study of theHeat Transfer to the Walls of a DI Diesel Engine". SAE Technical Paper 2005-01-0210, 2005.

34. F. Payri, X. Margot, A. Gil, and J. Martin. "Prediction of Heat Transfer to the Walls in DI Diesel Engines". Proceedings of the 2nd EACC International European Automotive CFD Conference, Frankfurt, 2005.

35. J. Benajes, E. Reyes, and J.M. Lujan. "Modelling Study of the Scavenging Process in a Turbocharged Diesel Engine with Modified Valve Operation". Proceedings of the Institution of Mechanical Engineers Part C: Journal of Mechanical Engineering Science, Vol. 210, pp. 383-393, 1996, doi: 10.1243/PIME PROC 199621021002.

36. "JANAF Thermodynamical Tables". DOW Chemical Company, 1962, Addendum, 1966.

37. R.J. Kee, F.M. Rupley, and J.A. Miller. "The Chemkin Thermodynamic Data Base". Sandia Report, SAND87-8215B, 1991.

38. J. Arregle, J.J. Lopez, J.M. Garcia, and C. Fenollosa. "Development of a Zero-Dimensional Diesel Combustion Model - Part 1 Analysis of the Quasi-Steady Diffusion Combustion Phase". Applied Thermal Engineering, Vol. 23, pp. 1301-1317, 2003. doi: 10.1016/S1359-4311(03)00079-6

39. J. Arregle, J.J. Lopez, J.M. Garcia, and C. Fenollosa. "Development of a Zero-Dimensional Diesel Combustion Model - Part 2 Analysis of the Transient Initial and Final Diffusion Combustion Phases". Applied Thermal Engineering, Vol. 23, pp. 1319-1331, 2003, doi: 10.1016/S13594311(03)00080-2. 
40. J.E. Dec. "A Conceptual Model of DI Diesel Combustion Based on Lasersheet Imaging". SAE Technical Paper 970873, 1997.

41. H. Hiroyasu, T. Kadota, and M. Arai. "Development and Use of a Spray Combustion Modeling to Predict Diesel Engine Efficiency and Pollutant Emissions - Part 1 Combustion Modeling". Bulletin of the Japan Society Mechanical Engineering,Vol. 26, pp. 569-575, 1983.

42. I. Wiebe. "Halbempirische Formel fur die Verbrennungs-Geschwindigkeit". Verlag der Akadimie der Wissenschaften der Vd SSR, Moscow, 1956.

43. J.R. Serrano, H. Climent, C. Guardiola, and P. Piqueras. "Methodology for Characterisation and Simulation of Turbocharged Diesel Engines Combustion During Transient Operation - Part 2: Phenomenological Combustion Simu-lation". Applied Thermal Engineering, Vol. 29, pp. 150-158, 2009.

44. J. Galindo, J.M. Lujan, J.R. Serrano, V. Dolz, and S. Guilain. "Description of a Heat Transfer Model Suitable to Calculate Transient Processes of Turbocharged Diesel Engines with OneDimensional Gas-Dynamic Codes". Applied Thermal Engineering, Vol. 26, pp.66-76, 2006.

45. C. Depcik and D. Assanis. "A Universal Heat Transfer Correlation for Intake and Exhaust Flows in a Spark-Ignition Internal Combustion Engine". SAE Technical Paper 2002-01-0372, 2002.

46. J.A. Caton and J.B. Heywood. "An Experimental and Analytical Study of Heat Transfer in an Engine Exhaust Port". International Journal of Heat and Mass Transfer, Vol. 24, pp. 581-895, 1981.

47. M. Reyes. "Modelo de Transferencia de Calor Para Colectores de Escape de Motores Alternativos". PhD Thesis, Universidad Politecnica de Valencia, Valencia, 1994.

48. W.M. Kays and A.L. London. "Compact Heat Exchangers". McGraw Hill Book Company, Second Edition, New York, 1964.

49. G. Martin, V. Talon, P. Higelin, A. Charlet, and C. Caillol. "Implementing Turbomachinery Physics into Data Map-Based Turbocharger Models". SAE Technical Paper 2009-01-0310, 2009.

50. T. Boger and A.K. Heibel. "Heat Transfer in Conductive Monolith Structures". Chemical Engineering Science, Vol. 60, pp. 1823-1835, 2005, doi: 10.1016/j.ces.2004.11.031.

51. A.G. Konstandopoulos, E.A. Kladopoulou, S.L. Yang, J.H. Johnson, and G.G. Parker. "A Study Describing the Performance of Diesel Particulate Filters During Loading and Regeneration - A Lumped Parameter Model for Control Applications". SAE Technical Paper 2003-01-0842, 2003.

52. A.G. Konstandopoulos, M. Kostoglou, E. Skaperdas, E. Papaioannou, D. Zarvalis, and E. Kladopoulou. "Fundamental Studies of Diesel Particulate Filters - Transient Loading, Regeneration and Aging". SAE Technical Paper 2000-01-1016, 2000.

53. R. Hilpert. "Experimental Study of Heat Dissipation of Heated Wire and Pipe in Air Current". Forschungsarbeiten auf dem Gebiete des Ingenieur - Wesens - Ausgabe A, Vol.4, No.5, pp.215224, 1933.

54. P.A. Konstantinidis, G.C. Koltsakis, and A.M. Stamatelos. "Transient Heat Transfer Modelling in Automotive Exhaust Systems". Proceedings of the Institution of Mechanical Engineers Part C: Journal of Mechanical Engineering Science, Vol. 211, No.1, pp. 1-15, 1997.

55. A.J. Chapman. "Heat Transfer". Macmillan Publishing Company, New York, 1960.

56. M. Tancrez, J. Galindo, C. Guardiola, O. Varnier, P. Fajardo. "Adapted Turbine Maps for Turbocharger Engine Matching”. Experimental Thermal and Fluid Science, 35(1), pp. 146-153, 2011. Doi: 10.1016/j.expthermflusci. 2010.07.018.

57. M. Lapuerta, O. Armas, and J.J. Hernandez. "Diagnostic of D.I. Diesel Combustion from InCylinder Pressure Signal by Estimation of Mean Thermodynamic Properties of the Gas". Applied Thermal Engineering, Vol. 19, pp.513-529, 1999. 


\section{Contact Information}

Prof. José Galindo. CMT-Motores Térmicos. Universitat Politècnica de València. Camino de Vera s/n, 46022.Valencia. Spain. Email: galindo@mot.upv.es

\section{Acknowledgements}

The work presented in this paper has been funded by Spain's Ministerio de Ciencia y Tecnología through program TRA2007-65433.

\section{Definitions/Abbreviations}

$\begin{array}{ll}\text { EGR } & \text { Exhaust Gas Recirculation } \\ \text { HP } & \text { High Pressure } \\ \text { LP } & \text { Low Pressure } \\ \text { ACT } & \begin{array}{l}\text { Apparent Combustion } \\ \text { Time }\end{array} \\ \text { FEM } & \text { Filling \& Emptying Model } \\ \text { MVEM } & \text { Mean Value Engine Model } \\ \text { MVM } & \text { Mean Value Model }\end{array}$

